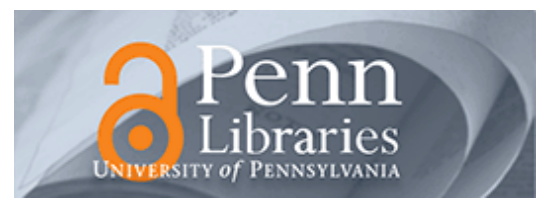

University of Pennsylvania

ScholarlyCommons

Management Papers

Wharton Faculty Research

$11-2017$

\title{
Economies of Scope, Resource Relatedness, and the Dynamics of Corporate Diversification
}

Arkadiy Sakhartov

University of Pennsylvania

Follow this and additional works at: https://repository.upenn.edu/mgmt_papers

Part of the Management Sciences and Quantitative Methods Commons

\section{Recommended Citation}

Sakhartov, A. (2017). Economies of Scope, Resource Relatedness, and the Dynamics of Corporate Diversification. Strategic Management Journal, 38 (11), 2168-2188. http://dx.doi.org/10.1002/smj.2654

This paper is posted at ScholarlyCommons. https://repository.upenn.edu/mgmt_papers/229

For more information, please contact repository@pobox.upenn.edu. 


\title{
Economies of Scope, Resource Relatedness, and the Dynamics of Corporate Diversification
}

\begin{abstract}
Research summary: The dominant view has been that businesses that are more related to each other are more often combined within diversified firms. This study uses a dynamic model to demonstrate that, with inter-temporal economies of scope, diversified firms are more likely to combine moderately related businesses than the most-related businesses. That effect occurs because strong relatedness reduces redeployment costs and makes firms redeploy all resources to better performing businesses. The strength of that effect depends on inducements for redeployment measured as the current return advantage of one business over another business, volatilities of business returns, and correlation of those returns. This study develops hypotheses for those relationships and suggests empirical operationalizations, encouraging empiricists to retest the implications of relatedness for the dynamics of corporate diversification.

Managerial summary: It is believed that diversified firms are more likely to combine more-related businesses because relatedness enables sharing of resources between businesses. Indeed, a firm can apply knowledge created in one business to another business, avoiding costly duplication in knowledge development. Resource sharing also adds value when a firm offers several products, adding the convenience of one-stop shopping and charging higher prices. However, resource sharing is not the only motivation for corporate diversification. In environments where profitability of businesses changes frequently, firms diversify by redeploying part of resources from an underperforming business to a better performing business. This study uses a dynamic model to demonstrate that, with that second motivation for corporate diversification, firms end up combining moderately related businesses rather than the mostrelated businesses.
\end{abstract}

\section{Keywords}

corporate diversification, resource-based view, resource relatedness, economies of scope, dynamic choice model.

Disciplines

Management Sciences and Quantitative Methods 


\title{
ECONOMIES OF SCOPE, RESOURCE RELATEDNESS, AND THE DYNAMICS OF CORPORATE DIVERSIFICATION
}

\author{
Arkadiy V. Sakhartov \\ The Wharton School \\ University of Pennsylvania \\ 2017 Steinberg Hall-Dietrich Hall \\ 3620 Locust Walk \\ Philadelphia, PA 19104-6370 \\ Phone (215) 7462047 \\ Fax (215) 8980401 \\ arkadiys@wharton.upenn.edu
}

Draft 4.0

October 22, 2015

I am grateful to Richard Bettis, Matthew Bidwell, Thomas Brush, Olivier Chatain, Shivaram Devarakonda, Supradeep Dutta, Emilie Feldman, Timothy Folta, Exequiel Hernandez, Daniel Levinthal, Marvin Lieberman, Katherine Maritan, Anoop Menon, Olga Petricevic, Jeffrey Reuer, Nicolaj Siggelkow, Lenos Trigeorgis, and Natalya Vinokurova for their valuable comments on the earlier versions of the manuscript. The study has benefitted from the feedback from participants of the $18^{\text {th }}$ International Conference on Real Options in Medellin (Colombia), the $12^{\text {th }}$ Atlanta Competitive Advantage Conference, and research seminars at the Leeds School of Business (the University of Colorado Boulder), the Stephen M. Ross School of Business (the University of Michigan), and the Warrington College of Business Administration (the University of Florida). I greatly appreciate the guidance offered by Constance Helfat and two anonymous reviewers at the Strategic Management Journal. I am also thankful to Wharton Computing for the provided computational resources and to the Management Department at the Wharton School for the financial support to the project. 
Economies of Scope, Resource Relatedness, and the Dynamics of Corporate Diversification

\title{
ECONOMIES OF SCOPE, RESOURCE RELATEDNESS, AND THE DYNAMICS OF CORPORATE DIVERSIFICATION
}

\begin{abstract}
The idea that relatedness between businesses enhances the tendency for diversifying firms to persistently combine those businesses dominated corporate diversification research. This study uses a dynamic model to qualify that proposition. The model considers alternative types of economies of scope and demonstrates that, with inter-temporal economies from redeployment of tangible resources, the effect of relatedness on diversification is very distinct from the assumed relationship. In particular, moderate rather than the strongest relatedness involved in intertemporal economies creates the strongest diversification propensity. Moreover, the effect of relatedness on that propensity depends on other determinants of economies of scope. The study develops hypotheses for those complex relationships and suggests empirical operationalizations, encouraging empiricists to retest the implications of relatedness for the dynamics of corporate diversification.
\end{abstract}

Keywords: corporate diversification; resource-based view; resource relatedness; economies of scope; dynamic choice model. 


\section{ECONOMIES OF SCOPE, RESOURCE RELATEDNESS, AND THE DYNAMICS OF CORPORATE DIVERSIFICATION}

\section{INTRODUCTION}

A key rationale for corporate diversification is that firms aim for economies of scope (Panzar and Willig, 1981; Teece, 1980). ${ }^{1}$ From the resource-based view of the firm (Penrose, 1959), such economies represent a reduction in costs for a firm deploying its resources in multiple businesses relative to the costs those businesses would incur if managed as independent firms. ${ }^{2}$ The resource-based economies were linked to resource relatedness, the similarity of resource requirements between businesses (Rumelt, 1974). Relatedness supports economies by enhancing the applicability of resources across the combined businesses and enabling the frugal use of the same resources (e.g., plants, employees, and technological and marketing knowledge) across those businesses (Hill, Hitt, and Hoskisson, 1992). In line with that logic, many empirical studies have confirmed that diversifying firms are more likely to enter more-related businesses (Anand, 2004; Chang, 1996; Neffke and Henning, 2013; Silverman, 1999; Wu, 2013; Zhou, 2011).

Despite the compelling empirical support to the idea that firms initiate diversification by entering related businesses, the evidence on the implications of relatedness for the resulting dynamics of corporate diversification has been decidedly mixed. ${ }^{3}$ On one hand, relatedness was argued to preserve combinations of businesses in the corporate scope (Bryce and Winter, 2009; Teece et al., 1994; Lien and Klein, 2013). That view was supported in studies verifying that firms are more likely to combine more-related businesses (Breschi, Lissoni, and Malerba, 2003; Fan and Lang, 2000; Lemelin, 1982). Moreover, relatedness of an entered business to other

\footnotetext{
${ }^{1}$ While focusing on economies of scope as a motive for diversification, this study only briefly discusses risk-reduction by firms (Amit and Livnat, 1988; Amit and Wernerfelt, 1990) and does not explicitly consider agency issues (Amihud and Lev, 1981).

${ }^{2}$ While recognizing the importance of demand-side economies of scope (Ye, Priem, and Alshwer, 2012) realized through the increased consumer willingness to pay for two products bundled by the same firm, the present study focuses on economies linked to the resource side of corporate diversification. Recent reviews of the research embracing the resource-based view on corporate diversification can be found in Hauschild and zu Knyphausen-Aufseß (2013) and Wan et al. (2001).

${ }^{3}$ Like in Helfat and Eisenhardt (2004), the dynamics of corporate diversification refer to the evolution of the corporate scope.
} 
businesses in the firm scope was shown to reduce the chances of subsequently exiting the entered business (Chang, 1996; Lien and Klein, 2013; O'Brien and Folta, 2009). On the other hand, relatedness of the combined businesses can destabilize the corporate scope. As Helfat and Eisenhardt (2004) argued, relatedness enables a firm to exit one business and enter another business, making the firm focused rather than diversified. Lee, Folta, and Lieberman (2010) were first to illustrate that relatedness of an entered business to a firm's other businesses raises the likelihood that the firm will exit the entered business. The opposing empirical findings introduced the ambiguity about the ultimate effect of relatedness on the probability that a firm will diversify into a pair of businesses. Besides the ambiguity about the ultimate effect of relatedness on the probability of diversification, two other issues listed in the first column of Table 1 were unresolved. Notably, the issues of whether relatedness alone suffices to predict the probability of diversification and how that probability evolves over time were not clear. The lack of clear answers to the three questions in the first column of Table 1 resulted from three respective limitations in previous research mentioned in the second column of the same table.

Insert Table 1 here

The first flaw was that, except for Lee et al. (2010), the previous views did not carefully discriminate the effects of relatedness on diversification between distinct types of economies of scope. That approach contrasted with Helfat and Eisenhardt (2004) who clarified that 'intertemporal' economies are very different from the often-studied 'intra-temporal' economies. While intra-temporal economies occur when a diversified firm contemporaneously shares its resources between related businesses, inter-temporal economies are realized when a firm exits one business and enters another related business by redeploying resources between them. ${ }^{4}$ The

\footnotetext{
${ }^{4}$ Although this study focuses on redeployment of resources between a firm's businesses, it does not explicitly consider resource redeployments between the acquirer and the target following a corporate acquisition (Capron, Dussauge, and Mitchell, 1998).
} 
restrictive focus on economies from the contemporaneous sharing of resources between related businesses led to the prevalent belief that relatedness between two businesses should enhance the probability that a firm will diversify into them (Bryce and Winter, 2009; Teece et al., 1994), inspiring multiple empirical tests (Breschi et al., 2003; Fan and Lang, 2000; Lemelin, 1982).

The second shortcoming was that the extant accounts implicitly assumed that the effect of relatedness on the patterns of corporate diversification was independent of other determinants of economies of scope. However, as Penrose (1959) argued, economies created in corporate diversification depend on the interaction of relatedness (reducing the costs of redeploying resources between businesses) with 'inducements,' the return advantages of one business over another. Such advantages represent an opportunity cost of the continued use of resources in a business performing worse than an alternative business. Sakhartov and Folta (2015) formally demonstrated that inducements moderate the effect of relatedness on economies of scope. As long as economies of scope determine corporate diversification decisions, inducements are also very likely to modify the effect of relatedness on the propensity of a firm to diversify.

The third limitation in the existing research was that the theory about how relatedness affects the dynamics of corporate diversification was largely informal. Nevertheless, verbal arguments can be 'very misleading' in the complex settings with inter-temporal links between a firm's choices (Ghemawat and Cassiman, 2007: 530). In the context of corporate diversification, such links are present between corporate scope decisions because resource redeployments are costly to reverse. As a result, a firm deciding to enter (or exit) a business considers not only the current redeployment costs but also the costs of a possible future exit from (or re-entry into) that business, making corporate diversification path-dependent (Sakhartov and Folta, 2014). The informal reasoning in that complex context included the tenuous assumption that, in contrast to 
relatedness linked to the sharing of resources, relatedness linked to resource redeployment may only have short-run implications for corporate diversification patterns (Bryce and Winter, 2009).

Considering the three limitations mentioned above, the current study collects the determinants of different types of economies of scope from the existing literature and develops a dynamic model of corporate diversification. Rooted in the general principle of dynamic optimality (Bellman, 1957), the model exploits the structural similarity of the allocation of resources across a set of businesses by firms to the allocation of wealth across a portfolio of securities by individual investors (Merton, 1969). ${ }^{5}$ The similarity enables the use of the simulation-based portfolio selection technique of Brandt et al. (2005) resolving not only the challenges of the informal reasoning in the complex corporate context but also the analytical intractability of diversification choices in the path-dependent setting (Haugh and Kogan, 2007).

The model derives several novel insights into the dynamics of corporate diversification listed in the last column of Table 1. First, the model identifies how the effect of relatedness on the probability of diversification depends on the type of economies of scope. With intratemporal economies, the diversification propensity is enhanced by relatedness. In contrast, with inter-temporal economies, the diversification propensity has an inverted U-shape relationship with relatedness: firms are most likely to persist with combinations of businesses having intermediate rather than the highest levels of relatedness. Moreover, the effects relatedness has on corporate scope with the two types of economies turn out to be interdependent. In particular, the relationship between relatedness involved in inter-temporal economies and the probability of diversification is most-concave with moderate levels of relatedness involved in intra-temporal

\footnotetext{
${ }^{5}$ Matsusaka (2001) applied the principle of dynamic optimality to corporate diversification, also highlighting the need to structure verbal arguments in the resource-based view using the principle of dynamic optimality (Matsusaka, 2001: 428). Other examples of elaborating the resource-based view on corporate diversification using the dynamic optimality are Bernardo and Chowdhry (2002), Kogut and Kulatilaka (1994), Sakhartov and Folta (2014; 2015), and Triantis and Hodder (1990).
} 
economies. Alternatively, the probability of diversification is unaffected by relatedness present in inter-temporal economies of scope when relatedness involved in intra-temporal economies is very low or very high. Second, the model indicates that inducements critically moderate the effect of relatedness on the diversification propensity. Finally, relatedness involved in intertemporal economies is shown to have very strong long-run implications for diversification. With moderate levels of relatedness present in inter-temporal economies, the probability of diversification grows over time and then keeps very high until the end of the resources' lifecycle.

The delivered results make three important contributions to corporate diversification research. First, the revealed difference in the effect of relatedness on diversification between intra-temporal and inter-temporal economies motivates researchers to unmerge those effects in empirical operationalizations and re-examine the often-tested relationship between relatedness and diversification. The later section of the paper provides some guidance on how to separately operationalize the two effects of relatedness. Second, the study is first to rigorously derive the complex relation between the diversification propensity and relatedness. The curvilinear relation involved in inter-temporal economies reconciles the findings that relatedness induces both the entry into and the exit from a business. The result also replaces the informal argument that firms are more likely to persist with sets of more-related businesses. Besides qualifying the oftentested hypothesis, the result reveals limitations of the recently advocated operationalization of relatedness based on the survival of business combinations (Bryce and Winter, 2009; Lien and Klein, 2013; Teece et al., 1994). When moderately-related businesses are more likely to be combined than strongly related businesses, inferring stronger relatedness from the co-occurrence of businesses in the corporate scope is tenuous. Third, the insight that inducements moderate the effect of relatedness on the diversification propensity necessitates the use of the interactions in 
empirical models predicting the probability and the direction of corporate diversification. This paper develops a set of hypotheses enabling the identification of the interactions between the previously-known determinants of economies of scope reviewed immediately below.

\section{DETERMINANTS OF ECONOMIES OF SCOPE}

Two recent elaborations enable a better identification of determinants of economies of scope. First, Helfat and Eisenhardt (2004) explained that, in addition to the often-cited 'intra-temporal' economies, firms use 'inter-temporal' economies. While intra-temporal economies occur when a firm contemporaneously shares resources between its businesses, inter-temporal economies are enacted when a firm withdraws all or part of its resources from one business (fully or partially exiting that business) and redeploys them to another business. Second, Levinthal and Wu (2010) clarified that intra-temporal economies involve 'scale free' intangible resources with no physical substance (e.g., technological and marketing knowledge). Such resources can be leveraged to new uses without withdrawing them from the original use. Conversely, inter-temporal economies involve 'non-scale free' tangible resources having constraints on their physical capacity (e.g., employees and manufacturing plants) and demanding the withdrawal from the original use to be redeployed to another use. Because firms' businesses comprise bundles of various resources (Penrose, 1959), diversification usually involves both types of economies. With both economies, relatedness, defined by Rumelt (1974) as the similarity of resource requirements between businesses, was identified as the key determinant (Hill et al., 1992).

\section{Relatedness and intra-temporal economies of scope}

With intra-temporal economies of scope, relatedness between businesses in the corporate scope promotes the applicability of the scale free knowledge across them (Bryce and Winter, 2009). 
Accordingly, a diversified firm can apply knowledge created in one business to another business, thereby avoiding the costly duplication in the development of the knowledge required in the two related businesses (Porter, 1987; Teece, 1980). While the applicability of knowledge across businesses hinges upon relatedness between them, there is no reason to assume that any level of relatedness results in positive economies. Because the knowledge transfer to receiving business units is costly (Maritan and Brush, 2003), such transfer costs can exceed small cost savings in unrelated diversification turning economies into diseconomies of scope. Conversely, in related diversification, the costs of the knowledge transfer are likely to fall behind strong economies.

\section{Relatedness and inter-temporal economies of scope}

With inter-temporal economies, relatedness promotes the applicability of non-scale free resources across the original and the new businesses. That enhanced cross-applicability leads to the following two effects. On one hand, relatedness reduces the current costs of redeploying non-scale free resources to the new business incurred in entering that business (Montgomery and Wernerfelt, 1988). On the other hand, relatedness enhances the reversibility of redeployment (or non-redeployment) by reducing the costs of a possible future reversal of that decision incurred in exiting the entered business (or entering that business later) (Sakhartov and Folta, 2015).

In addition to redeployment costs, economies realized in resource redeployment depend on 'inducements,' return advantages of one business over another (Penrose, 1959). Such advantages represent the opportunity cost of the continued deployment of a firm's resources in the original use underperforming the alternative business. Sakhartov and Folta (2015) summarize three dimensions of inducements used in the existing research. The first dimension, enhancing economies of scope, is the current return advantages in the new business (Anand, 2004; Silverman, 1999; Wu, 2013). The second dimension, raising the economies, is return volatilities 
(Kogut and Kulatilaka, 1994; Triantis and Hodder, 1990) in the current and the new businesses. Finally, economies of scope are reduced by return correlation between the current and the alternative businesses (Triantis and Hodder, 1990). The three dimensions capture the relative attractiveness of the alternative business for current or future resource redeployment. Sakhartov and Folta (2015) derived that the effect of relatedness on inter-temporal economies is strongly moderated by inducements and cannot be identified without accounting for such interactions.

\section{Implications of relatedness for corporate scope}

Based on the suggested impacts of relatedness on the value created in corporate diversification, multiple exploratory studies assessed the relation between relatedness of a pair of businesses and the probability that a firm will diversify into that pair. For instance, Lemelin (1982) examined diversification patterns of more than 2,000 Canadian firms in early 1970s. The study found that the probability of diversification in a pair of businesses is positively associated with relatedness measured as the similarity of distribution systems in those businesses based on input-output tables. Fan and Lang (2000) studied the probability of diversification into a pair of businesses from nearly 500 U.S. industries in years 1982, 1987, and 1992. They reported that diversifying firms are more likely to own more-related segments, with relatedness captured as the affiliation with the same two-digit U.S. Standard Industry Classification (SIC) code. That result was robustly confirmed in the same study with relatedness measured as the similarity in both inputs and outputs between the segment industries based on input-output tables. Finally, Breschi et al. (2003) explored the patterns of technological diversification in a large sample of firms in Europe and the U.S. in years between 1982 and 1993. That study demonstrated that a firm active in one technological field is more likely to participate in another field when the two fields are morerelated, with relatedness measured as co-occurrence of the two technological fields in patents. 
Despite some empirical evidence on the impact of relatedness on diversification patterns, the tests providing that evidence were based on the underdeveloped theory. In particular, the theory built off the assumption that the positive effect of relatedness on economies of scope translates into an unconditional positive effect of relatedness on the corporate scope. Notably, Teece et al. (1994: 5) 'assume that activities which are more related will be more frequently combined within the same corporation.' Subsequent work further explicated that assumption:

We assume that each industry a diversified firm includes in its portfolio will affect firm performance. We refer to the performance effects of these combinations as the relatedness... related industries are more frequently combined in firms than unrelated industries. (Lien and Klein, 2013: 1480)

Bryce and Winter (2009: 1573) explained that the benefits of sharing scale free knowledge between related businesses (i.e., intra-temporal economies of scope) preserve corporate diversification into those businesses for a long time. In contrast, the benefits of redeploying nonscale free resources between related businesses (i.e., inter-temporal economies of scope) were assumed to have, at most, short-run implications (Bryce and Winter 2009: 1573).

To sum up, the existing theory about the impact of relatedness on the dynamics of corporate diversification, as well as the empirical tests relying on that theory, had three important features illustrated in the third column of Table 1. First, the existing theory assumed, rather than carefully derived, that the probability of diversification is strongly positively associated with relatedness. Second, the effect of relatedness between two businesses on the propensity of a firm to diversify into those businesses was implicitly assumed independent of other determinants of economies of scope (i.e., inducements). Finally, the implications of relatedness occurring with inter-temporal economies of scope were deemed unimportant in the long run. The next section builds the model that enables the development of the theory free of those tenuous assumptions. 


\section{DYNAMIC MODEL OF CORPORATE DIVERSIFICATION}

To scrutinize the implications of relatedness for corporate diversification, this section builds a dynamic model. The approach, rooted in the principle of dynamic optimality (Bellman, 1957), was common to rationalize investors' lifetime allocation of wealth across a portfolio of securities (Merton, 1969) and was extended to corporate diversification (Bernardo and Chowdhry, 2002; Kogut and Kulatilaka, 1994; Matsusaka, 2001; Sakhartov and Folta, 2014; 2015; and Triantis and Hodder, 1990). Resembling an investor keeping all her wealth in a single security, the firm in the model is initially focused on one business deploying all its resources in product market $i$. As an investor can allocate her cash to another security, so can the firm use its resources in an alternative product market $j .{ }^{6}$ Specifically, scale free resources can be shared between $i$ and $j$. Non-scale free resources may be fully or partially withdrawn from $i$ and redeployed to $j$, or vice versa, at any time $t$ before the end of the resource lifecycle $t=T$. Proportions $m_{i t}$ and $m_{j t}=1-m_{i t}$ of non-scale free resources used respectively in markets $i$ and $j$ at time $t$ represent corporate diversification choices, with $m_{i t}$ serving as a single control variable. ${ }^{7}$ Like a sequence of investment decisions by an individual investor in the portfolio choice model, the chain $\left\{m_{i t}\right\}_{t=0}^{T-1}$ of corporate diversification choices represents the policy function in this model.

The corporate context specified in the model involves the pertinent determinants of economies of scope. In particular, the model includes the three dimensions of inducements: the current return advantage, return volatilities, and return correlation. Relatedness is modeled using

\footnotetext{
${ }^{6}$ Corporate diversification can unfold through a sequence of entries into more than one additional business, wherein firms may end up with a portfolio of less-related businesses even though each entry in the sequence was related. That intriguing scenario is not explicitly considered in the model. While exploring that possibility is interesting, adding more businesses to the current model would substantially extend the computation time and distract the focus from the specific gaps outlined in Table 1 . The model follows prior research (Kogut and Kulatilaka, 1994; Triantis and Hodder, 1990) and focuses on one alternative business.

${ }^{7}$ There is no need to specify proportions of scale free resources since such resources are levered infinitely between the markets and cannot be used in isolation from non-scale free resources.
} 
its two ramifications, the ease of sharing of scale free knowledge (present in intra-temporal economies of scope) and the costs of redeployment of non-scale free resources (present in intertemporal economies of scope). Redeployment costs make diversification choices path-dependent (i.e., payoff to future choices depend on current choices) and, hence, intractable not only qualitatively (Ghemawat and Cassiman, 2007) but also analytically (Haugh and Kogan, 2007). The structural similarity of the dynamic allocation of corporate resources to the dynamic portfolio choice model (Merton, 1969) and the generality of the principle of dynamic optimality (Bellman, 1957) enable the use of a numerical method originally developed to optimize the dynamic portfolio choices. In particular, the intractability is resolved with the simulation-based technique of Brandt et al. (2005) illustrated in van Binsbergen and Brandt (2007).

To use the method of Brandt et al. (2005), the model represents returns $C_{i t}$ and $C_{j t}$ in product markets $i$ and $j$ at time $t$ as two random state variables evolving in discrete time. The model simulates a large number of paths for $C_{i t}$ and $C_{j t}$, with realizations $C_{k i t}$ and $C_{k j t}$ on path $k$ at time $t$. Accordingly, proportions $m_{k i t}$ and $m_{k j t}=1-m_{k i t}$ capture a diversification choice on path $k$ at time $t$. The sequence $\left\{m_{k i t}\right\}_{t=0}^{T-1}$ of diversification choices on path $k$ is identified by using the dynamic programming approach (Bellman, 1957). Namely, starting with time $t=T-1$ when a diversification choice can be made the last time before the end of the resource lifecycle, the model finds on each path proportion $m_{k i t}^{*}$ that maximizes a Taylor approximation of the value function, the utility of the value the firm accumulates over the lifecycle of its resources by allocating those resources between the two businesses. Like in van Binsbergen and Brandt (2007), the coefficients for the Taylor series are estimated by running the ordinary least square regression of the value function realized at $t=T$ on a polynomial of the state variables at time 
$t=T-1$. The algorithm then proceeds recursively from $t=T-1$ to $t=0$. To apply the method of Brandt et al. (2005) to the present study, two extensions are introduced. First, because unlike Brandt et al. (2005) and van Binsbergen and Brandt (2007) the present study is not particularly interested in explicating the policy function, the diversification choices are summarized across all paths as the probability that the firm is diversified at time $t$. Second, the algorithm is replicated for multiple sets of the determinants of economies of scope to derive how the found probability of diversification is affected by those determinants. Key elements of the model, the corporate context and the identification of diversification choices, are elaborated below.

\section{Corporate context}

In the model, at every time $t$ the firm seeks to maximize the value function $U_{t}$ of the terminal value $V_{T}$ accumulated through resource deployment choices $\left\{m_{i s}\right\}_{s=t}^{T-1}$ undertaken over the remaining lifecycle of the firm's resources. Formally, the problem the firm faces is:

$$
U_{t}=\max _{\left\{m_{i s}\right\}_{s=t}^{T-1}} E_{t}\left[u\left(V_{T}\right)\right]
$$

In Equation 1, $E_{t}[\cdot]$ is the expectation based on the information available at time $t$. The function $u(\cdot)$ captures the utility of the risk-averse firm from having value $V_{T}$ given the risk attached to that value. The property of risk-aversion is common for individuals optimizing the allocation of wealth across risky securities. There are several reasons for extending that assumption to firms. First, firms' choices were shown to be driven by risk preferences of their key stakeholders: chief executive officers (Cronqvist, Makhija, and Yonker, 2012), key managers (Koller, Lovallo, and Williams, 2012), or large shareholders (Faccio, Marchica, and Mura, 2011). Second, the idea replaces the restrictive assumption that firms make uniform choices based on risk-neutrality. The uniformity would contrast with the actual heterogeneity of resolutions for the same corporate 
challenges. ${ }^{8}$ Finally, concave utility functions have been repeatedly used in the literature (e.g., Asplund, 2002; Carceles Poveda, 2003; Choudhary and Levine, 2010; Loehman and Nelson, 1992; Meunier 2014) to specify the tradeoff between risk and returns faced by firms. The model applies the prevalently used utility function with constant absolute risk aversion (Arrow, 1971):

$$
u\left(V_{T}\right)=1-e^{-\gamma V_{T}}
$$

where $\gamma$ is the coefficient capturing risk aversion. ${ }^{9}$ That parameter has an intuitive interpretation that its higher value implies that the firm puts a greater discount for the risk associated with $V_{T}$.

Like van Binsbergen and Brandt (2007), the model specifies the state variables (i.e., the market returns) $C_{i t}$ and $C_{j t}$ as a vector autoregression with one lag VAR(1). That discrete-time stochastic process captures linear interdependence between univariate autoregressions AR(1) often used to empirically capture the evolution of a random variable. Formally,

$$
\left[\begin{array}{l}
C_{i t} \\
C_{j t}
\end{array}\right]=\left[\begin{array}{l}
A_{i} \\
A_{j}
\end{array}\right]+\left[\begin{array}{cc}
\mu_{i i} & 0 \\
0 & \mu_{j j}
\end{array}\right]\left[\begin{array}{l}
C_{i t-1} \\
C_{j t-1}
\end{array}\right]+\left[\begin{array}{l}
\varepsilon_{i t} \\
\varepsilon_{j t}
\end{array}\right] .
$$

Equation 3 involves the dimensions of inducements used in the literature. Thus, intercepts $A_{i}$ and $A_{j}$ capture the current return advantage $\left(A_{j}-A_{i}\right) / A_{i}$. Errors $\varepsilon_{i t}$ and $\varepsilon_{j t}$ have variances $\sigma_{i}^{2}$ and $\sigma_{j}^{2}$ and correlation $\rho$ capturing return volatilities and correlation, respectively. With Equation 3, $C_{i t}$ and $C_{j t}$ are realized in $T+1$ points in time $t \in[0, T]$. In the context void of economies of scope, an arbitrary realization $k$ of returns $C_{k i t}$ and $C_{k j t}$ and deployment of proportions $m_{k i t}$ and

\footnotetext{
${ }^{8}$ For example, facing the decline in the newspaper business, Belo Corporation completely withdrew from that business in 2002 to switch to broadcasting; while The Washington Post Co. persisted with that business. Also, facing the collapse in the snowmobile business in early 1970s, dozens of snowmobile businesses exited that business forever; whereas Bombardier Inc. withdrew only part of its resources from snowmobiles and persisted with that business until 2003.

${ }^{9}$ The chosen utility is common in portfolio selection (Çanakoğlu and Özekici, 2009; Henderson, 2005; Muthuraman and Kumar, 2006). That utility has a property that $u\left(V_{T}+\alpha\right)=f(\alpha) u\left(V_{T}\right)+g(\alpha)$, where $\alpha$ is a constant; and $f(\cdot)$ and $g(\cdot)$ are functions independent of $V_{T}$. That property enables modelers to ignore $\alpha$, making complex optimization feasible.
} 
$\left(1-m_{k i t}\right)$ of resources in markets $i$ and $j$, respectively, would generate the net return at time $t$ :

$$
F_{k t}=\left[m_{k i t} C_{k i t}+\left(1-m_{k i t}\right) C_{k j t}\right]
$$

Relatedness is modeled using its known impacts on the two types of economies of scope. With inter-temporal economies, relatedness reduces redeployment costs. Such costs represent a loss in efficiency present in withdrawing non-scale free resources from another business and redeploying them to a focal business relative to returns earned when the resources had been originally used in the focal business (Montgomery and Wernerfelt, 1988). Because the model captures efficiency with market returns, total costs of redeployment of resources to market $j(i)$ at time $t$ are modeled as a product of (a) the marginal redeployment cost $S$ of a unit of resources; (b) the amount $\max \left[0, m_{k i t-1}-m_{k i t}\right]\left(\max \left[0, m_{k i t}-m_{k i t-1}\right]\right)$ of resources redeployed to market $j(i)$ between $t-1$ and $t$; and (c) average returns $\hat{C}_{j t}\left(\hat{C}_{i t}\right)$ at time $t$ in the recipient business. That specification of redeployment costs has precedents: Sakhartov and Folta (2014; 2015) modeled redeployment costs as a proportion of returns in the receiving unit. Kogut and Kulatilaka (1994) also modeled switching costs as a proportion of value outcomes, although in their model such outcomes are captured with average production costs. ${ }^{10}$ Thus, with intertemporal economies, the net return earned by the firm at time $t$ is

$$
F_{k t}=\left[m_{k i t} C_{k i t}+\left(1-m_{k i t}\right) C_{k j t}\right]-S\left\{\max \left[0, m_{k i t}-m_{k i t-1}\right] \hat{C}_{i t}+\max \left[0, m_{k i t-1}-m_{k i t}\right] \hat{C}_{j t}\right\}
$$

With intra-temporal economies, relatedness increases the applicability of scale free knowledge between businesses (Bryce and Winter, 2009). Therefore, the firm can use knowledge from one business in another business, thereby reducing total costs (Porter, 1987; Teece, 1980) and increasing net returns. Small cost savings in unrelated diversification can be exceeded by the

\footnotetext{
${ }^{10}$ Like in Kogut and Kulatilaka (1994) and Sakhartov and Folta (2014; 2015), S does not depend on the direction of redeployment between $i$ and $j$. The assumption captures the idea that such costs are reduced by relatedness of a pair of businesses.
} 
costs of transferring the knowledge to the receiving business (Maritan and Brush, 2003), turning economies into diseconomies. Alternatively, large cost savings in related diversification surpass the costs of the knowledge transfer, creating positive economies. Those two polar scenarios for intra-temporal economies can be represented as a continuum amending Equation 5 as follows

$$
\begin{aligned}
& F_{k t}=\left[m_{k i t} C_{k i t}+\left(1-m_{k i t}\right) C_{k j t}\right]-S\left\{\max \left[0, m_{k i t}-m_{k i t-1}\right] \hat{C}_{i t}+\max \left[0, m_{k i t-1}-m_{k i t}\right] \hat{C}_{j t}\right\}+ \\
& I(\beta-1)]\left(m_{k i t} \hat{C}_{i t}+\left(1-m_{k i t}\right) \hat{C}_{j t}\right)
\end{aligned}
$$

In Equation 6, $I$ is an indicator of knowledge sharing: $I=1$ if $0<m_{k i t}<1$, and $I=0$ otherwise.

Coefficient $\beta$ is the sharing factor directly capturing the effect of relatedness on intra-temporal economies. When $\beta<1, i$ and $j$ are weakly related and diversification creates diseconomies.

When $\beta=1, i$ and $j$ are moderately related and the firm generates neither economies nor diseconomies. When $\beta>1, i$ and $j$ are strongly related and diversification creates economies. The specification of relatedness in intra- temporal economies has precedents. In particular, Sakhartov and Folta (2014) also modeled intra-temporal economies with the sharing factor. ${ }^{11}$ The representation of relatedness imposes no dependence structure between $S$ and $\beta$. Although a strong negative relationship might be assumed because relatedness is defined as the general similarity of resource requirements between two businesses (Rumelt, 1974: 29), the model avoids assuming that strong negative relationship for several reasons. First, the extant theory does not argue that two businesses using similar scale free resources should necessarily rely on equally similar non-scale free resources. Second, by not imposing a specific structure on the underexplored relationship between $S$ and $\beta$, the model remains agnostic about the nature

\footnotetext{
${ }^{11}$ There are two reasons for specifying intra-temporal economies of scope as a proportion of average rather than actual market returns. First, that specification precludes intra-temporal economies from being negative for reasons other than low relatedness. That measure is needed because, with $\operatorname{VAR}(1) C_{i t}$ or $C_{j t}$ (in contrast to $\hat{C}_{i t}$ or $\hat{C}_{j t}$ ) may have a negative realization. A negative realization may occur when the demand for the product in market $i$ or $j$ drops. That drop, however, will not eliminate cost savings from the knowledge sharing. Second, the specification is aligned with the specification of inter-temporal economies.
} 
of that relationship. That approach enables the flexibility in examining the dynamic impact of relatedness on diversification for any dependence structure, instead of making the restrictive assumption. Finally, a later section of the current study uses industry data and introduces some tentative evidence of the lack of a decisively strong negative relationship between $S$ and $\beta$.

The value dynamics in the context with intra-temporal and inter-temporal economies are shown in Table 2 for the case $T=10$. The first row indicates how value $V_{t}$ accumulated by time $t$ evolves over time and how that value derives from the net return on investment $F_{t}$. To isolate economies of scope from the option to buy new resources, returns are not reinvested in markets $i$ and $j$ but are put into a risk-free account with interest rate $r$. The second row splits the total value $V_{T}$ accumulated over the resource lifecycle into the past (normal font) and the future (bold font) parts at time $t$. With the property of the utility described in Footnote 9, only the future part $\tilde{V}_{T}$ shown in the third row is relevant for the identification of diversification choices.

\section{Insert Table 2 here}

\section{Identification of corporate diversification choices}

Non-trivial redeployment costs $(S>0)$ make diversification path-dependent (i.e., the payoff to future choices depends on a current choice), precluding the analytical identification of the policy function (Haugh and Kogan, 2007). The intractability is resolved using the simulation-based technique of Brandt et al. (2005) relying on the principle of dynamic optimality (Bellman, 1957) and illustrated in van Binsbergen and Brandt (2007). Five steps in van Binsbergen and Brandt (2007) are amended with two last steps summarizing the diversification propensity. Moreover, the algorithm is replicated for numerous combinations of the determinants of economies of scope to identify how those determinants individually and jointly affect the diversification propensity. 
- Step 1. Simulate $n$ of paths for $C_{i t}$ and $C_{j t}$ based on Equation 3. Discretize proportion $m_{k i t} \in[0,1]$ of resources deployed in $i$ with a grid $m_{k i t} \in\{0,1 / L, 2 / L, \ldots,(L-1) / L, 1\}$, where $L$ is a discretization number. Estimate mean returns $\hat{C}_{i t}$ and $\hat{C}_{j t}$ for Equation 6 .

- Step 2. Take path $k$ and consider time $t=T-1$ when returns are earned the last time. For a current diversification choice $m_{k i T-1}$ and a most recent choice $m_{k i T-2}$ taken from their discretized values, use Equation 6 and Table 2 to estimate value $\tilde{V}_{k T}$ relevant for the optimization of the diversification choice $m_{k i T-1}$. Repeat the estimation of $\tilde{V}_{k T}$ for each of $n$ paths. Use Equation 2 to compute utility $u\left(\tilde{V}_{k T}\right)$. Assemble the dataset consisting of $n$ combinations of $u\left(\tilde{V}_{k T}\right), C_{k i T-1}$, and $C_{k j T-1}$. Run an ordinary least square regression model such that $u\left(\tilde{V}_{k T}\right)=\beta_{0}+\beta_{1} C_{k i T-1}+\beta_{2} C_{k j T-1}+\beta_{3} C_{k i T-1}^{2}+\beta_{4} C_{k j T-1}^{2}+\beta_{5} C_{k i T-1} * C_{k j T-1}+\psi .^{12}$

- Step 3. Using the coefficients ( $\beta$ 's) estimated in Step 2, compute, on each path, the expected utility $\hat{u}(\cdot)=E\left[u\left(\tilde{V}_{k T}\right) \mid\left(C_{k i T-1}, C_{k j T-1}, m_{k i T-1}, m_{k i T-2}\right)\right]$ conditioned on the firm being on path $k$, having previously committed choice $m_{k i T-2}$, and committing choice $m_{k i T-1}$.

- Step 4. Repeat Steps 2 and 3 for all values of $m_{k i T-1}$ and $m_{k i T-2}$. Take values of $\hat{u}(\cdot)$ calculated for a particular value of $m_{k i T-2}$ and, among them, select an optimal current choice $\left(m_{k i T-1}^{*} \mid m_{k i T-2}\right)=\arg \max _{m_{k T-1}} \hat{u}(\cdot)$ conditioned on the considered most recent choice $m_{k i T-2}$. Repeat Step 4 for all values of the most recent diversification choice $m_{k i T-2}$.

- Step 5. Using the dynamic programming principle, proceed recursively backward from $t=T-2$ to $t=0$ with Steps 2, 3, and 4 and retrieve the matrix of diversification choices

\footnotetext{
12 The model involves the second-order Taylor expansion of the utility function. Error $\psi$ is normally distributed with zero mean.
} 
$\left(m_{k i t}^{*} \mid m_{k i t-1}\right)$ on all $n$ paths conditioned on the most recent choices. In calculating value $\tilde{V}_{k T}$ relevant for the optimization of diversification choices, use Equation 6 and Table 2.

- Step 6. Given that the firm is initially focuses on market $i$, proceed recursively forward from $t=0$ to $t=T-1$ through the conditional diversification choices $\left(m_{k i t}^{*} \mid m_{k i t-1}\right)$ derived in Steps 5 and calculate the matrix of unconditional choices $\left\{m_{k i t}^{*}\right\}_{t=0}^{T-1}$. Each of $n$ columns of that matrix represents the policy function on path $k$. All columns together represent the policy function for all $n$ states of the state variables $C_{i t}$ and $C_{j t}$ over time.

- Step 7. Use the matrix of unconditional choices from Step 6 and estimate the probability $p_{t}=\operatorname{Pr}\left[\left\{m_{k i t}^{*} \neq 0 \cap m_{k i t}^{*} \neq 1\right\}\right]$ of diversification at time $t$ by dividing the number of cases where the firm is not fully focused on either $i$ or $j$ at time $t$ by the total number of possible scenarios $n$. On each path $k$, the longevity of diversification $l_{k}$ is counted as the number of periods when the firm diversifies. The mean longevity is $\hat{l}=\sum_{k=1}^{n} l_{k} / n$.

\section{RESULTS}

The analysis of the impact of relatedness on the dynamics of corporate diversification involves steps addressing the issues raised in Table 1. First, the diversification propensity is derived for various sets of the sharing factor and the marginal redeployment cost representing relatedness, while keeping other parameters constant. That design identifies separate and joint effects of the two roles of relatedness on the diversification propensity. Second, the diversification propensity is assessed for multiple combinations of the determinants of inter-temporal economies, when intra-temporal economies are disallowed. In that step, the interactions between inducements and 
redeployment costs in determining the diversification propensity are explicated. Finally, the evolution of the diversification propensity is traced over time, and the sensitivity of that propensity to redeployment costs is checked at the end of the resource lifecycle. That analysis uncovers the long-run implications of relatedness with inter-temporal economies.

\section{Implications of relatedness for diversification propensity}

A key aim of the present study is to scrutinize the idea that relatedness unambiguously enhances the diversification propensity. Figure 1 illustrates the diversification propensity with two parameters, the probability that the firm is diversified in the middle of the resource lifecycle (Panel A) and the average longevity of diversification (Panel B). In each panel, inter-temporal economies of scope are represented with the marginal redeployment cost, varying continuously from its lowest possible value (i.e., the strongest relatedness) to a very high value (i.e., very weak relatedness). Intra-temporal economies are captured with the sharing factor, taking five discrete values. A very low factor (i.e., very weak relatedness) is shown with the broken lines capturing very strong intra-temporal diseconomies of scope. A slightly-below-medium factor is shown with the lines with downward-pointing triangles illustrating weak intra-temporal diseconomies. A moderate factor is revealed with the solid lines capturing the lack of intra-temporal economies or diseconomies. A slightly-above-medium factor is shown with the lines with upward-pointing triangles displaying weak intra-temporal economies. Finally, a very high factor (i.e., very strong relatedness) is demonstrated with the lines with plus signs revealing very strong intra-temporal economies. Three patterns summarize the effects of relatedness on the diversification propensity.

Insert Figure 1 here

First, Figure 1 reveals that the lines with a higher sharing factor are always located at least as high as the lines with a lower factor. The observed relative altitudes of the lines imply 
that, with intra-temporal economies, relatedness monotonously enhances both the probability and the longevity of diversification. That first result is not novel: it confirms the existing insight that relatedness of scale free knowledge between businesses increases the propensity of the firm to diversify into those businesses. However, the magnitude of the divergence of the solid lines from zero in Figure 1 is surprising. The strong divergence suggests that the firm is very likely to persistently diversify even when relatedness of knowledge between the combined businesses is mediocre, generating no intra-temporal economies of scope. In particular, when intra-temporal economies are absent, the probability of diversification can reach the value of 99 percent and such diversification can last for up to 95 percent of the resource lifecycle. Because of the model design, in the absence of intra-temporal economies, the diversification illustrated with the solid lines in Figure 1 occurs due to inter-temporal economies of scope.

Second, most of the lines in Figure 1 have inverted U-shapes. That curvature suggests that, with inter-temporal economies, moderate rather than the strongest relatedness leads to the highest probability and the greatest longevity of corporate diversification. That result challenges the assumed generality of the monotonous positive relationship between relatedness and the diversification propensity. While contrasting with the extant theory, the derived curvature can be intuitively explained based the dual role of relatedness with inter-temporal economies of scope.

- With very strong relatedness, (a) the cost of the current redeployment of resources to another business is dispensable and (b) the decision to redeploy or not to redeploy resources is fully reversible. Even a tiny return advantage in another business suffices to make the firm redeploy all resources to that business. As a result, the firm permanently changes between being focused on the original business to being focused on the new business. Alternatively, a tiny disadvantage in another business motivates the firm to wait 
for a better future opportunity for redeployment. In both scenarios, the firm is more likely to be focused rather than diversified (explaining the left parts of the curves in Figure 1).

- With very weak relatedness, (a) the cost of the current redeployment is prohibitively high and (b) that redeployment would be very costly to reverse. As a result, the firm waits for a rare opportunity to redeploy all resources to the much better performing alternative business, remaining focused on the original business in the vast majority of the realizations of the uncertain returns (explaining the right parts of the curves in Figure 1).

- With intermediate relatedness, both (a) the cost of the current redeployment and (b) the cost of reversing the redeployment or the non-redeployment decision are moderate. The firm envisions interchanging scenarios with advantages and disadvantages of the alternative business over time. The optimal decision for the value-maximizing firm in that case is to economize on the current redeployment cost and the possible future cost of reversing redeployment or non-redeployment. Accordingly, the firm rations the amount of redeployed resources and redeploys a portion of them to another business, the exact portion that will remain in that business until the end of the resources' lifecycle. As a result, the firm becomes persistently diversified (explaining the peaks in Figure 1). Third, the lines in Figure 1 vary in concavity. Notably, the lines with moderate levels of the sharing factor are concave. Conversely, the lines with very low or very high factor are flat. With very high sharing factor on the lines with plus signs, the firm instantly redeploys part of resources to a new business to receive very strong intra-temporal economies. The firm then keeps diversifying regardless of redeployment costs. With very low sharing factor on the broken lines, the firm is reluctant to incur very strong diseconomies and therefore never redeploys resources to the new business regardless of redeployment costs. With mediocre sharing factor, 
the firm is indifferent to the trivial intra-temporal economies but is very sensitive to the magnitude of redeployment costs determining inter-temporal economies of scope. That third pattern in Figure 1 means that the effects relatedness has on corporate diversification with intratemporal and inter-temporal economies are interdependent, necessitating the empirical operationalization of the interdependence in models predicting corporate diversification patterns.

\section{Implications of inducements for diversification propensity}

Although relatedness has been a primary focus for the research on corporate diversification, the implications of other determinants of economies of scope (i.e., inducements) for the dynamics of diversification should also be explicated. That clarification would be particularly necessary if the effect of relatedness on the diversification propensity depended on inducements. Whether such interdependences are present is analyzed below for each of the dimensions of inducements.

\section{Current return advantage}

Figure 2 presents the implications of the current return advantage for the probability (Panel A) and the longevity (Panel B) of diversification. The broken lines and the lines with downwardpointing triangles are close to the zero level indicating that, with negative current advantages, the diversification propensity is low and only marginally affected by redeployment costs. The result is intuitive: the firm is reluctant to switch resources to a substantially underperforming business regardless of redeployment costs. While the lowest diversification propensity corresponds to the strong current disadvantage, the figure fails to demonstrate a robust direct effect of the current advantage on corporate diversification. For example, with low redeployment costs, the strongest diversification propensity results from the zero current advantage. In turn, with high costs of redeployment, the positive current advantage leads to the strongest diversification propensity. 
Despite the unclear direct effect, the current return advantage systematically alters the effect of redeployment costs on the diversification propensity: with greater current advantages, a peak in that propensity shifts to higher redeployment costs. That shift has the following intuition.

- Strong current advantages combined with low redeployment costs make the firm instantly switch all resources to another market. The effect is seen in the flat parts of the lines with plus signs where the firm is focused. With higher redeployment costs, the firm rations the amount of redeployed resources to cut current redeployment costs and possible future costs of reversing it. As a result, the firm switches only part of resources becoming diversified. The tendency occurs in the upward-sloping parts of the lines with plus signs.

- If current return advantages are weaker, the firm is less motivated to redeploy all resources to another business and the rationing of the amount of redeployed resources (i.e., partial redeployment leading to diversification) starts with lower redeployment costs, as in the lines with upward-pointed triangles and the solid lines in Figure 2.

\section{Return volatility}

Figure 3 illustrates the effect of return volatility on the diversification propensity. Volatility affects the diversification propensity in two ways. First, with particular redeployment costs, the lines with higher volatility often appear above the lines with lower volatility, implying a direct positive effect on the diversification propensity. That effect corresponds to the insight of the portfolio theory (Markowitz, 1959) suggesting that the greater variance of more--volatile returns creates a stronger motivation for a risk-averse agent to diversify the associated risks.

Insert Figure 3 here

Second, the arms of a line in Figure 3 are further apart from each other, the higher is volatility associated with that line. That second pattern, unenlightened by the portfolio theory, is 
unique to inter-temporal economies of scope. The pattern suggests that return volatility can significantly extend values of relatedness in inter-temporal economies with which diversification is highly likely. In particular, the range of redeployment costs resulting in the probability of diversification greater than 75 percent is six times broader with very high volatility than with low volatility. The effect, also present in the longevity of diversification, can be explained as follows. The firm faces the oscillation of relative returns in another business between advantages and disadvantages, with the magnitude of the realized differences depending on return volatility.

- With low volatility, confidence bands for returns are narrow and return advantages and disadvantages are weak in most scenarios. The loss from not having redeployed resources would be relatively low; whereas, in redeployment, the firm would have to instantly pay some cost. In that case, very low redeployment costs (below even a weak advantage) make the firm redeploy all resources to another business. However, even moderate costs of redeployment would exceed a weak advantage in another business and discourage the firm from the initial redeployment, explaining why the downward-sloping increments of the lines with low volatility are positioned quite close to the left margins in Figure 3.

- With high volatility, confidence bands for returns are broad and both strong advantages and strong disadvantages are abundant. In that case, the firm decides between (a) instantly redeploying resources to the currently much-better-performing business, but likely facing the need to costly redeploy resources back in the future; and (b) waiting for even greater advantages in another business, but possibly losing the greatest advantage. Facing that dilemma, the firm maximizing total inter-temporal economies cautiously accepts higher redeployment costs and redeploys part of resources, explaining the shift of the downward-sloping increments of the lines to higher redeployment costs. 


\section{Return correlation}

Figure 4 demonstrates the effect of return correlation on the diversification propensity. That propensity bears upon correlation in two ways. First, with particular redeployment costs, lines with more-negative correlation appear above lines with more-positive correlation, revealing a direct negative effect on the diversification propensity. That effect is aligned with the portfolio theory (Markowitz, 1959) in that that more-positive return correlation leads to a greater variance of returns (i.e., the risk) of a portfolio of assets, reducing the utility of diversification.

Insert Figure 4 here

Second, the arms of a line in Figure 4 are more distant from each other, the morenegative is correlation on that line. Unexplored by the portfolio theory, that effect is an attribute of inter-temporal economies of scope. The effect suggests that correlation significantly contains values of relatedness in inter-temporal economies, with which corporate diversification is likely. Thus, the range of redeployment costs resulting in the probability of diversification greater than 75 percent is three times broader with strong negative correlation than with zero correlation. The extension, also revealed in the longevity of diversification, has the following intuition.

- With positive correlation, market returns are close to each other and scenarios with strong advantages or disadvantages are rare. In that case, moderate costs suffice to discourage the firm from initial redeployment making the firm focus in most scenarios. That is why the lines with weak positive correlation decline close to the left margins in Figure 4.

- With negative correlation, market returns diverge from each other and strong advantages and disadvantages are present. In that case, the firm faces the same dilemma as with high volatility. Maximizing total inter-temporal economies, the firm accepts higher costs and switches part of resources, shifting the declining increments to the right. 
To sum up, inducements alter how relatedness involved in inter-temporal economies affects the diversification propensity. Notably, the peak in such a propensity shifts to higher redeployment costs when another business currently more-strongly outperforms the existing business. The effect extends on a broader range of redeployment costs when the businesses have more-volatile returns. The effect extends on a broader range of redeployment costs when the businesses have more-negatively correlated returns. Accordingly, the effect of relatedness on diversification cannot be reliably identified unless its interactions with inducements are captured.

\section{Evolution of diversification propensity with different types of economies of scope}

The last candidate for the scrutiny of the effect of relatedness on diversification is the claim that, unlike intra-temporal economies, inter-temporal economies from redeploying non-scale free resources between related businesses has only short-run implications (Bryce and Winter, 2009: 1573). The model can test that claim by separately tuning relatedness involved in intra-temporal and inter-temporal economies of scope and tracing the probability of diversification over time.

Figure 5 reveals the long-run implications of relatedness. Panel A presents the effect of redeployment costs on the likelihood of diversification at the end of the resource lifecycle. Intratemporal economies are disallowed. Relatedness involved in inter-temporal economies strongly affects the probability of diversification even at the end of the lifecycle. In particular, the inverted U-shape relationship robustly confirmed in Figures 1-4 persists by the end of the lifecycle. Moreover, the magnitude of the relation continues to be very strong: the probability of diversification varies between zero and 99 percent depending on the value of redeployment costs.

Insert Figure 5 here

Panel B of Figure 5 depicts the dynamics of the probability of diversification when relatedness present in inter-temporal economies assumes a mediocre value. Three scenarios for 
intra-temporal economies are modeled: (a) economies are strong (the line with plus signs), (b) neither economies nor diseconomies are present (the solid line), and (c) diseconomies are strong (the broken line). The striking difference in the elevation between the line with plus signs and the broken line confirms that relatedness of scale free resources between businesses has a strong and long-lasting positive effect on diversification into those businesses (Bryce and Winter, 2009: 1573). However, the dynamics illustrated with the solid line, representing the context void of intra-temporal economies, contrast with the existing conception that inter-temporal economies of scope may only have a short-run effect on corporate diversification. In the absence of intratemporal economies, moderate relatedness involved in inter-temporal economies makes the probability of diversification grow over time and then keeps it very high (96\%) in the long run.

\section{Validation of results}

A substantial effort has been put to verify that the model is adequate to corporate settings. First, the model uses concepts often applied in corporate diversification research. Second, in capturing those concepts, the model builds off the modelling precedents. Third, the model reconfirms the main idea of the extant theory and only qualifies it by considering the previously ignored issues. Fourth, every new result is given an intuitive interpretation. Fifth, multiple robustness tests were run to check whether the results are due to the particular specification. As common in sensitivity analyses of simulation models, results in each figure were re-estimated for alternative values of parameters held constant in the baseline estimation. The directions of all the results have been reconfirmed. ${ }^{13}$ Finally, the later section compares the most intriguing result of the inverted Ushape relationship with the patterns of corporate diversification observed in the U.S. industries.

\footnotetext{
${ }^{13}$ In addition, returns were modeled as geometric Brownian or mean-reverting processes. Also, the non-negativity constraint on the accumulated value was established. Finally, total redeployment costs were modeled as a fixed value. Results of the robustness checks are available upon request.
} 


\section{Summary of new theoretical results}

The following hypotheses summarize the new theoretical results amending the existing theory. H1: The propensity to diversify in two businesses has an inverted U-shape relationship with relatedness involved in inter-temporal economies of scope between those businesses.

H2: The inverted U-shape relationship between the propensity to diversify in two businesses and relatedness involved in inter-temporal economies of scope is strongest when relatedness involved in intra-temporal economies of scope is moderate.

H3: The inverted U-shape relationship between the propensity to diversify in two businesses and relatedness involved in inter-temporal economies of scope sifts to lower levels of such relatedness with stronger current return advantages.

H4: The inverted U-shape relationship between the propensity to diversify in two businesses and relatedness involved in inter-temporal economies of scope expands onto a broader range for such relatedness with higher return volatilities.

H5: The inverted U-shape relationship between the propensity to diversify in two businesses and relatedness involved in inter-temporal economies of scope expands onto a broader range for such relatedness with more-negative return correlation.

\section{TOWARDS EMPIRICAL IDENTIFICATION OF THEORETICAL RESULTS}

Empirical models seeking to test the implications of relatedness for the dynamics of corporate diversification, elaborated with Hypotheses 1-5, can take the following form:

$$
\begin{aligned}
& Y=\gamma_{0}+\gamma_{1} K+\gamma_{2} \beta_{i j}+\gamma_{3} S_{i j}+\gamma_{4} \beta_{i j}^{2} S_{i j}^{2}+\gamma_{5}\left(C_{j t}-C_{i t}\right)+\gamma_{6}\left[S_{i j}+\gamma_{7}\left(C_{j t}-C_{i t}\right)\right]^{2} \\
& +\gamma_{8} \sigma_{i}+\gamma_{9} \sigma_{i} S_{i j}^{2}+\gamma_{10} \sigma_{j}+\gamma_{11} \sigma_{j} S_{i j}^{2}+\gamma_{12} \rho_{i j}+\gamma_{13} \rho_{i j} S_{i j}^{2}+\varepsilon
\end{aligned} .
$$

The dependent variable $Y$ may be captured as the probability of the co-occurrence of businesses $i$ and $j$ in the corporate scope or the duration of that combination. Businesses can be identified 
based on the U.S. SIC. All $\gamma$ 's are estimated coefficients. By $K$, a vector of determinants of the diversification propensity other than those used in this study is denoted. The sharing factor $\beta_{i j}$ can be measured with the Euclidean distance between patent profiles of SIC industries created by Brian Silverman. That measure (detailed in the Appendix) inversely captures the similarity of the scale free technological knowledge between industries. Redeployment costs $S_{i j}$ can be measured as the Euclidian distance between industries $i$ and $j$ in non-scale free resources (detailed in the Appendix). Current returns $C_{i t}$ and $C_{j t}$ can be taken from the Compustat Segments as mean industry return on asset (ROA) at time $t$. Volatilities $\sigma_{i}$ and $\sigma_{j}$ can be computed as standard deviations of industry ROA. Return correlation $\rho_{i j}$ can be measured as correlation of mean ROA between industries. Finally, the distribution of the error term $\varepsilon$ is chosen based on the used dependent variable, the probability of the co-occurrence or the duration of the co-occurrence.

Hypotheses $\mathrm{H} 1-\mathrm{H} 5$ are tested by checking the signs of the respective $\gamma$ 's. Based on the theoretical results derived in the present study, the expected signs of the coefficients are the following: $\gamma_{4}>0(\mathrm{H} 2), \gamma_{6}<0(\mathrm{H} 1), \gamma_{7}<0(\mathrm{H} 3), \gamma_{9}<0$ and $\gamma_{11}<0(\mathrm{H} 4)$, and $\gamma_{13}>0(\mathrm{H} 5)$.

\section{DISCUSSION}

Does relatedness between businesses enhance the tendency for a diversifying firm to persistently combine them? The existing theory answered that question affirmatively (Bryce and Winter, 2009; Lien and Klein, 2013; Teece et al., 1994). The direct relationship, inferred from the positive impact of relatedness on intra-temporal economies of scope from knowledge sharing, has been tested empirically (Breschi et al., 2003; Fan and Lang, 2000; Lemelin, 1982). However, there has also been recognition of inter-temporal economies of scope, with which relatedness 
can destabilize the corporate scope making firms exit some businesses to enter related businesses (Helfat and Eisenhardt, 2004; Lee et al. 2010; Penrose, 1959; Sakhartov and Folta, 2014). With that insight, the ultimate effect of relatedness on the dynamics of diversification is less certain than previously believed. In addition, determinants of economies of scope other than relatedness were argued to interact with relatedness in creating economies (Penrose, 1959; Sakhartov and Folta, 2015) and therefore can alter the effect of relatedness on the diversification propensity. To improve the understanding of the effect of relatedness on the dynamics of diversification, this study builds the dynamic model of diversification choices including both types of economies of scope. The model delivers several stimulating insights for the corporate diversification research.

First, the model identifies separate and joint effects of relatedness on the diversification propensity with the two types of economies of scope. As known before, that propensity is enhanced by relatedness of scale free knowledge involved in intra-temporal economies. In contrast, with inter-temporal economies, the diversification propensity has an inverted U-shape relationship with relatedness. That means that firms are most likely to persist with pairs of businesses having intermediate rather than the highest relatedness of non-scale free resources. Moreover, the two effects of relatedness are interdependent. In particular, the diversification propensity is most sensitive to relatedness present in inter-temporal economies when relatedness involved in intra-temporal economies is moderate. The difference between the two effects of relatedness on corporate diversification, along with the interdependence between those effects, necessitates the separate operationalizations of the two manifestations of relatedness and the reexamination of the often-tested relationship between diversification and relatedness.

Second, relatedness alone does not suffice to predict the proclivity of a firm to diversify. Inducements significantly moderate the effect of relatedness. The derived interactions suggest 
that the effect of relatedness on diversification cannot be empirically identified, unless its interactions with inducements are captured. The study summarizes the empirical relationships and provides the direction for their empirical operationalization, laying the groundwork for a better empirical identification of the determinants of the diversification propensity.

Finally, the paper uncovers the dynamics of diversification based on inter-temporal economies involving non-scale free resources. In contrast to the extant view, the diversification propensity remains very sensitive to relatedness of non-scale free resources in the long run. With moderate relatedness present in inter-temporal economies, the firm diversifies, even when intratemporal economies from sharing scale free knowledge are absent. Moreover, such propensity grows rather than declines over time. Beyond revising the idea that relatedness of non-scale free resources may only have short-run effect on diversification (Bryce and Winter, 2009), the result warns about the limitations of the recently advocated measure of relatedness based on survival of business combinations (Bryce and Winter, 2009; Lien and Klein, 2013; Teece et al., 1994). The risk of inferring relatedness from the survival of business combinations is illustrated below.

\section{Relationship between diversification propensity and relatedness in U.S. industries}

This section provides some tentative evidence of the relation between the proclivity of U.S. firms to diversify and the two effects of relatedness. The diversification propensity is computed as the mean time of combining two U.S. SIC industries within a firm's scope based on the Compustat Segments in years 1976-2013. The sharing factor, representing intra-temporal economies, is estimated using patent profiles of U.S. SIC industries. That operationalization (described in the Appendix) captures the similarity between industries in scale free technological knowledge classified into categories (e.g., Explosives; Basic Electric Elements; and Optics). Redeployment costs, capturing un-relatedness in inter-temporal economies, are computed using profiles of U.S. 
SIC industries in tangible resources. The measure (detailed in the Appendix) considers the dissimilarity between industries in non-scale free resources classified into categories of tangible resources in Compustat (e.g., Inventories; Property, Plant, and Equipment; Cash and Short-term Investments). The relationship between the two proxies for relatedness is illustrated in Figure 6 .

Insert Figure 6 here

The distribution of the data points in Figure 6 indicates that different combinations of the two effects of relatedness are present in U.S. industries. The declining regression line displays a negative relation between the sharing factor and redeployment costs. That relation was expected because relatedness makes general resource requirements in two industries similar, facilitating both knowledge sharing and resource redeployment. Although the revealed relation is significant statistically ( $\mathrm{p}-$ value $<0.001)$, its magnitude is weak. The weakness of the relation between the two effects of relatedness implies that two businesses using similar scale free knowledge do not necessarily rely on equally similar non-scale free resources. The revealed weak relation also suggests that the two manifestations of relatedness can be disentangled empirically.

Figure 7 shows the time of combining industries against the two effects of relatedness between them. If the believed simple relationship where relatedness enhances the diversification propensity were true, the graph would have one peak (Panel A). With actual data (Panel B), there is indeed a peak in the top left corner revealing the persistence of pairs of strongly related businesses. However, there is another peak where the two proxies are moderate. Accordingly, the long survival of pairs of moderately related businesses, advocated as the measure of relatedness, may be erroneously classified as revealing strong relatedness. The second peak with mediocre sharing factors and redeployment costs matches the peak in the solid line in Panel B of Figure 1. Insert Figure 7 here 


\section{Limitations}

The present study builds the dynamic model of diversification choices to improve the understanding of how the dynamics of corporate diversification bear upon resource relatedness. Nevertheless, the used methodology has some intrinsic limitations. The generalizability of the results derived numerically may be compromised by arbitrary choices of the model's parameters. The current study, like other studies using simulation, attempts to mitigate the concern about the generalizability by undertaking extensive sensitivity checks and confirming that the directions of all the reported relationships are robust in a wide variety of parameter specifications.

In addition, the practical significance of the theoretically derived relationships depends on their strength relative to other predictors of the diversification propensity in real corporate contexts. Although the previous section reports the tentative evidence from the real industry setting consistent with the main derived result, the illustration falls short of controlling for multiple alternative predictors of the diversification propensity. Future empirical work should use more sophisticated empirical models to ascertain whether the reported effects of relatedness on the proclivity of firms to diversify are statistically significant in representative samples.

Some readers may find the used model of diversification too simplistic because it ignores time lags in resource allocation, organizational inertia, bounded rationality of corporate managers, competitive advantages of incumbent or new firms in entered businesses, and possible acquisitions and divestitures of resources. While adding those features would enrich the enquiry, they would also considerably complicate the model making it intractable even numerically. Future research might try building more comprehensive models of corporate diversification.

Finally, the focus on economies of scope confronts the tenet that corporate diversification is redundant because stock market investors can, by themselves, diversify their investment 
portfolios. While general inapplicability of that tenet to corporate strategy has been already explained (Conundrum \#1 in Bettis, 1983); the present study considers how active managerial strategies can extract value unavailable to undiversified firms and, accordingly, their investors.

\section{Conclusion}

The present paper scrutinizes the implications of resource relatedness for the dynamics of corporate diversification. The benchmark for the scrutiny is the very prevalent belief that firms are more likely to diversify in combinations of more-related businesses, because relatedness enhances intra-temporal economies of scope from contemporaneously sharing scale free knowledge between combined businesses. The study uses the dynamic model of diversification choices to reconsider that proposition. The model follows recent research and involves the effects relatedness has on the diversification propensity with various types of economies of scope. The model demonstrates that, with inter-temporal economies from redeployment of nonscale free resources, the effect of relatedness on the diversification propensity remarkably differs from what is commonly assumed. In particular, with inter-temporal economies, moderate rather than the strongest relatedness leads to the strongest diversification propensity. Moreover, the effect of relatedness involved in inter-temporal economies on the diversification propensity is critically moderated by other determinants of inter-temporal economies of scope and by relatedness involved in intra-temporal economies. The study develops empirically testable hypotheses for those complex relationships importantly qualifying the commonly tested, simple proposition that firms are more likely to diversify in more-related businesses. The paper also suggests empirical operationalizations for the developed hypotheses. Those developments can encourage empiricists to retest the dynamic implications of relatedness for corporate diversification. 


\section{REFERENCES}

Amit R, Livnat J. 1988. Diversification strategies, business cycles and economic performance. Strategic Management Journal 9(2): 99-110.

Amit R, Wernerfelt B. 1990. Why do firms reduce business risk? Academy of Management Journal 33(3): 520-533.

Anand J. 2004. Redeployment of corporate resources: A study of acquisition strategies in the US defense industries, 1978-1996. Managerial and Decision Economics 25(6/7): 383-400.

Arrow KJ. 1971. Essays in the Theory of Risk-Bearing. Markham: Chicago, IL.

Asplund M. 2002. Risk-averse firms in oligopoly. International Journal of Industrial Organization 20(7): 995-1012.

Bellman R. 1957. Dynamic Programming. Princeton University Press: Princeton, NJ.

Bernardo AE, Chowdhry B. 2002. Resources, real options, and corporate strategy. Journal of Financial Economics 63(2): 211-234.

Bettis RA. 1983. Modern financial theory, corporate strategy and public policy: Three conundrums. Academy of Management Review 8(3): 406-415.

Brandt MW, Goyal A, Santa-Clara P, Stroud JR. 2005. A simulation approach to dynamic portfolio choice with an application to learning about return predictability. Review of Financial Studies 18(3): 831-873.

Breschi S, Lissoni F, Malerba F. 2003. Knowledge-relatedness in firm technological diversification. Research Policy 32(1): 69-87.

Bryce DJ, Winter SG. 2009. A general interindustry relatedness index. Management Science 55(3): 1570-1585.

Çanakoğlu E, Özekici S. 2009. Portfolio selection in stochastic markets with exponential utility functions. Annals of Operations Research 166(1): 281-297.

Capron L, Dussauge P, Mitchell W. 1998. Resource redeployment following horizontal acquisitions in Europe and North America, 1988-1992. Strategic Management Journal 19(7): 631-661.

Carceles Poveda E. 2003. Capital adjustment costs and firm risk aversion. Economics Letters 81(1): 101-107. 
Chang CJ. 1996. An evolutionary perspective on diversification and corporate restructuring: Entry, exit, and economic performance during 1981-89. Strategic management Journal 17(8): 587-611.

Choudhary MA, Levine P. 2010. Risk-averse firms and employment dynamics. Oxford Economic Papers 62(3): 578-602.

Cronqvist H, Makhija AK, Yonker SE. 2012. Behavioral consistency in corporate finance: CEO personal and corporate leverage. Journal of Financial Economics 103(1): 20-40.

Faccio M, Marchica MT, Mura R. 2011. Large shareholder diversification and corporate risktaking. The Review of Financial Studies 24(11): 3601-3641.

Fan JPH, Lang LHP. 2000. The measurement of relatedness: An application to corporate diversification. The Journal of Business 73(4): 629-660.

Ghemawat P, Cassiman B. 2007. Introduction to the special issue on strategic dynamics. Management Science 53(4): 529-536.

Haugh MB, Kogan L. 2007. Duality theory and approximate dynamic programming for pricing American options and portfolio optimization. In Handbook in Operations Research and Management Science, Volume 15, Birge JR, Linetsky V (eds). Elseiver B.V.: Amsterdam, The Netherlands: 925-948.

Hauschild S, zu Knyphausen-Aufseß D. 2013. The resource-based view of diversification success: conceptual issues, methodological flaws, and future directions. Review of Managerial Science 7(3):327-363.

Helfat CE, Eisenhardt KM. 2004. Inter-temporal economies of scope, organizational modularity, and the dynamics of diversification. Strategic Management Journal 25(13): 1217-1232.

Henderson V. 2005. The impact of the market portfolio on the valuation, incentives and optimality of executive stock options. Quantitative Finance 5(1): 35-47.

Hill CWL, Hitt MA, Hoskisson RE. 1992. Cooperative versus competitive structures in related and unrelated diversified firms. Organization Science 3(4): 501-521.

Kogut B, Kulatilaka N. 1994. Operating flexibility, global manufacturing, and the option value of a multinational network. Management Science 40(1): 123-139.

Koller T, Lovallo D, Williams Z. 2012. Overcoming a bias against risk. McKinsey Quarterly 4: $15-17$.

Lee G, Folta TB, Lieberman M. 2010. Relatedness and market exit. Working paper. Available at: http://papers.ssrn.com/sol3/papers.cfm?abstract_id=1612190. 
Lemelin A. 1982. Relatedness in the patterns of interindustry diversification. The Review of Economics and Statistics 64(4): 646-657.

Levinthal DA, Wu B. 2010. Opportunity costs and non-scale free capabilities: profit maximization, corporate scope, and profit margins. Strategic Management Journal 31(7): 780-801.

Lien LB, Klein PG. 2013. Can the Survivor Principle Survive Diversification? Organization Science 24(5): 1478-1494.

Loehman E, Nelson C. 1992. Optimal risk management, risk aversion, and production function properties. Journal of Agricultural and Resource Economics 17(2): 219-231.

Maritan CA, Brush TH. 2003. Heterogeneity and transferring practices: implementing flow manufacturing in multiple plants. Strategic Management Journal 24(10): 945-959.

Markowitz HM. 1959. Portfolio Selection: Efficient Diversification of Investment. John Wiley: New York.

Matsusaka JG. 2001. Corporate diversification, value maximization, and organizational capabilities. Journal of Business 74(3): 409-431.

Merton RC. 1969. Lifetime portfolio selection under uncertainty: The continuous-time case. The Review of Economics and Statistics 51(3): 247-257.

Meunier G. 2014. Risk aversion and technology portfolios. Review of Industrial Organization 44(4): 347-365.

Montgomery CA, Wernerfelt B. 1988. Diversification, Ricardian rents, and Tobin's q. RAND Journal of Economics 19(4): 623-632.

Muthuraman K, Kumar S. 2006. Multidimensional portfolio optimization with proportional transaction costs. Mathematical Finance 16(2): 301-335.

Neffke F, Henning M. 2013. Skill relatedness and firm diversification. Strategic Management Journal 34(3): 297-316.

O’Brien J, Folta T. 2009. Sunk costs, uncertainty and market exit: A real options perspective. Industrial and Corporate Change 18(5): 807-833.

Panzar JC, Willig RD. 1981. Economies of Scope. American Economic Review 71(2): 268-272.

Penrose ET. 1959. The Theory of the Growth in the Firm. John Wiley: New York.

Porter ME. 1987. From competitive advantage to corporate strategy. Harvard Business Review 65(3): 43-59. 
Rumelt RP. 1974. Strategy, Structure, and Economic Performance, Harvard University Press: Boston, MA.

Sakhartov AV, Folta TB. 2014. Resource relatedness, redeployability, and firm value. Strategic Management Journal 35(12): 1781-1797.

Sakhartov AV, Folta TB. 2015. Getting beyond relatedness as a driver of corporate value. Strategic Management Journal, forthcoming.

Silverman BS. 1999. Technological resources and the direction of corporate diversification: Toward an integration of the resource-based view and transaction cost economics. Management Science 45(8): 1109-1124.

Teece DJ. 1980. Economies of scope and the scope of the enterprise. Journal of Economic Behavior and Organization 1(3): 223-247.

Teece DJ, Rumelt R, Dosi G, Winter S. 1994. Understanding corporate coherence: theory and evidence. Journal of Economic Behavior and Organization 23(1): 1-30.

Triantis AJ, Hodder JE. 1990. Valuing flexibility as a complex option. Journal of Finance 45(2): 549-565.

Van Binsbergen JH, Brandt MW. 2007. Solving dynamic portfolio choice problems by recursing on optimized portfolio weights or on the value function? Computational Economics 29(3-4): 355-367.

Wan W, Hoskisson R, Short J, Yiu D. 2011. Resource-based theory and corporate diversification: Accomplishments and opportunities. Journal of Management 37(5): 1335-1368.

Wu B. 2013. Opportunity costs, industry dynamics, and corporate diversification: Evidence from the cardiovascular medical device industry, 1976-2004. Strategic Management Journal 34(11): 1265-1287.

Ye G, Priem RL, Alshwer AA. 2012. Achieving demand-side synergy from strategic diversification: How combining mundane assets can leverage consumer utilities. Organization Science 23(3): 207-224.

Zhou YM. 2011. Synergy, coordination costs, and diversification choices. Strategic Management Journal 32(6): 624-639. 


\section{APPENDIX: Operationalizations of resource relatedness with U.S. industry data}

The sharing factor, representing relatedness in intra-temporal economies, is estimated using

patent profiles of 3-digit U.S. SIC industries compiled by Brian Silverman. The measure

assumes that sharing technological (scale free) knowledge is easier between industries with

more-similar knowledge requirements. Accordingly, knowledge dissimilarity between industries

$i$ and $j$ is quantified as an Euclidean distance: $S_{i j}^{P}=\sqrt{\sum_{a}\left(P_{i a}-P_{j a}\right)^{2}}$, where $P_{i a}\left(P_{j a}\right)$ is the

frequency of patents from category $a$ being used in industry $i(j)$. To directly capture the ease of

the knowledge sharing, the distance is then subtracted from its highest possible value and scaled

by that value. The mean (median) of the final measure of the sharing factor is $54 \%(57 \%){ }^{14}$

Redeployment costs, representing relatedness in inter-temporal economies, are estimated

with industry profiles of tangible assets as follows. Balance sheet data are taken from Compustat

for firms present in 1989-1996. Then, intangibles are eliminated. A firm's industry is defined as

the main 3-digit SIC code. Finally, for industry $i$, the value of assets of category $b$ is summed

up, and its weight $Q_{i b}$ in the total asset value in $i$ is computed. Because redeploying resources is

harder between industries with less-similar requirements, redeployment costs between industries

$i$ and $j$ are estimated as an Euclidean distance: $S_{i j}^{Q}=\sqrt{\sum_{b}\left(Q_{i b}-Q_{j b}\right)^{2}}$. The distance is then scaled

by its highest possible value. The mean (median) of the measure is $30 \%(27 \%){ }^{15}$

\footnotetext{
${ }^{14}$ While the measure of patent similarity was developed by Silverman (1999) to enhance the researchers' ability to effectively capture relatedness between two industries in terms of the knowledge involved, the measure has the following limitations. First, the measure is restricted to only one type of scale free resources, patented knowledge. There are other scale free resources $(e . g$., reputation and brand names), not included in the measure. Second, the database involves patents granted in 1990-1993. The contemporary patent structure may have changed since then.

${ }^{15}$ The offered measure of the cost of redeploying non-scale free resources has the following limitations. First, the SIC code used to compile an industry profile in terms of tangible resources is the main SIC code reported by firms in Compustat. That code pertains to single-business and multi-business firms. There are not enough single-business firms in the database to develop the measure across all pairs of industries. Second, there is a reservation in the description of the Compustat variable Intangible Assets that some intangibles may be captured by Property, Plant, and Equipment, when no breakdown for such assets is available.
} 


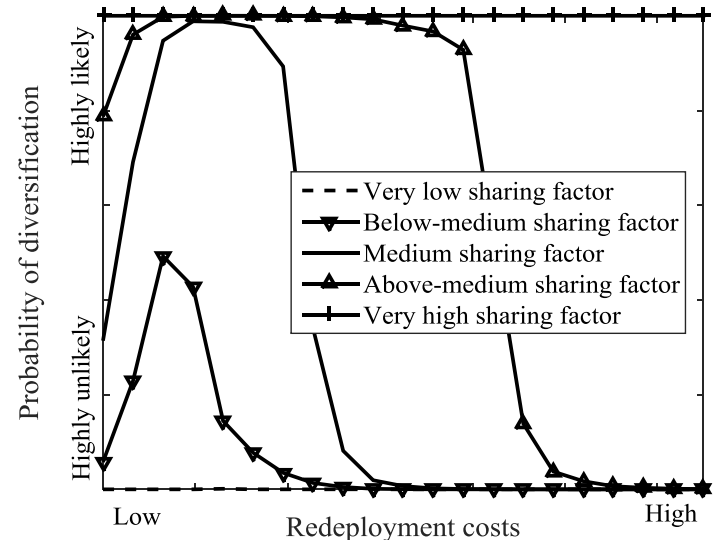

\section{A. Effects of redeployment costs and the sharing factor on the probability of corporate diversification}

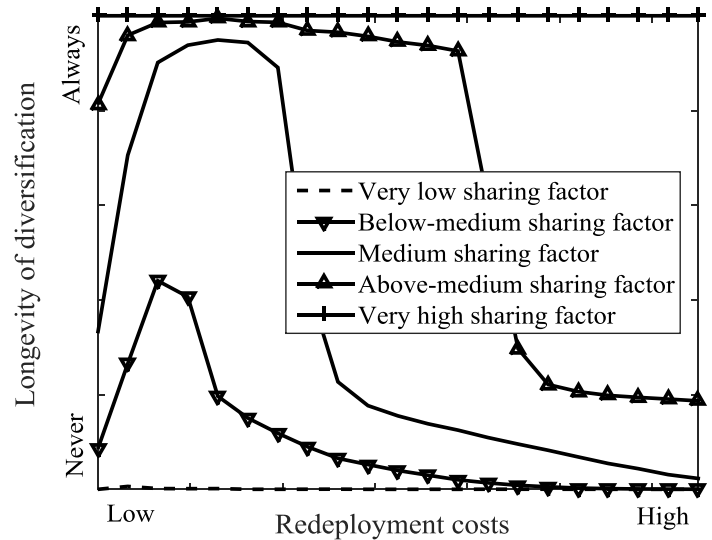

\section{B. Effects of redeployment costs and the sharing factor on the longevity of corporate diversification}

\section{Figure 1. Implications of relatedness for the dynamics of corporate diversification}

Figure 1 shows the probability $p_{t}$ of the firm being diversified in markets $i$ and $j$ in the middle of the resources lifecycle (Panel A), and the average longevity

$\hat{l}$ of such diversification (Panel B). In both panels, the first (inverse) proxy for relatedness, the marginal redeployment cost $S$, represents inter-temporal economies of scope and varies within the interval $S \in[0.0,1.3]$. In particular, $S=0.0$ corresponds to the strongest possible relatedness between $i$ and $j$ in non-scale free resources, whereas $S=1.3$ corresponds to very weak relatedness. In both panels, the second (direct) proxy for relatedness, the sharing factor $\beta$, represents intra-temporal economies of scope and takes five values $\beta \in\{0.90,0.99,1.00,1.01,1.0\}$. To clarify, with $\beta=0.90$ (depicted with the broken lines), $i$ and $j$ are very weakly related in scale free knowledge, resulting in strong intra-temporal diseconomies of scope. With $\beta=0.99$ (depicted with the lines with downward-pointing triangles), knowledge relatedness is slightly below average, resulting in weak diseconomies. With $\beta=1.00$ (depicted with the solid lines), knowledge relatedness is average, generating neither diseconomies nor economies. With $\beta=1.01$ (depicted with the lines with upward-pointing triangles), knowledge relatedness is slightly above average, creating weak economies. With $\beta=1.10$ (depicted with the lines with plus signs), $i$ and $j$ are very strongly related in knowledge, resulting in strong economies. The following values of other parameters were used to generate the graphs: the length of the resource lifecycle, $T=10$; the coefficient of absolute risk aversion, $\gamma=0.5$; the discreteness with which resource capacity may be redeployed, $L=10$; the offsets capturing the current returns, $A_{i}=A_{j}=0.50$; the trends for returns, $\mu_{i i}=\mu_{j j}=0.1$; the variances of the innovation terms capturing the volatilities of returns, $\sigma_{i}^{2}=\sigma_{j}^{2}=0.45$; the correlation of the innovation terms capturing the correlation of returns, $\rho=0$; the number of simulated paths for the returns, $n=10,000$; the risk-free interest rate, $r=0.1$; and the value of the invested resources, $V_{0}=1$. 


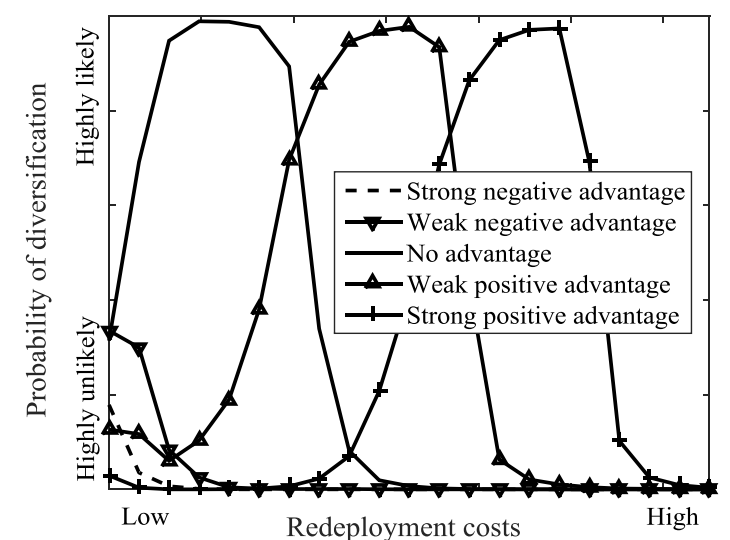

\section{A. Effects of redeployment costs and the current return advantage on the probability of diversification}

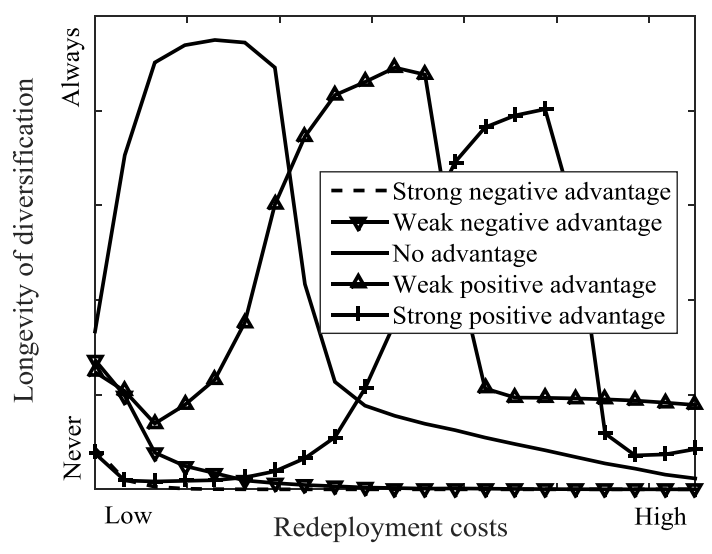

B. Effects of redeployment costs and the current return advantage on the longevity of diversification

\section{Figure 2. Implications of redeployment costs and the current return advantage for the dynamics of corporate diversification}

Figure 2 shows the probability $p_{t}$ of the firm being diversified in markets $i$ and $j$ in the middle of the resources lifecycle (Panel A), and the average longevity

$\hat{l}$ of such diversification (Panel B). In both panels, the first (inverse) proxy for relatedness, the marginal redeployment cost $S$, represents inter-temporal economies of scope and varies within the interval $S \in[0.0,1.3]$. In particular, $S=0.0$ corresponds to the strongest possible relatedness between $i$ and $j$ in non-scale free resources, whereas $S=1.3$ corresponds to very weak relatedness. In both panels, the second proxy for relatedness, the sharing factor $\beta$, is set to the medium value $\beta=1.00$ with which knowledge relatedness is mediocre and intra-temporal diseconomies or economies are absent. In both panels, the current return advantage $\left(A_{j}-A_{i}\right) / A_{i}$ takes five values. In particular, in the broken lines, $A_{i}=0.50$ and $A_{j}=0.40$ showing the strong negative current advantage. In the lines with downward-pointing triangles, $A_{i}=0.50$ and $A_{j}=0.45$ revealing the weak negative current return advantage. In the solid lines, $A_{i}=A_{j}=0.50$ capturing the zero current advantage. In the lines with upward-pointing triangles, $A_{i}=0.50$ and $A_{j}=0.55$ showing the weak positive current advantage. In the lines with plus signs, $A_{i}=0.50$ and $A_{j}=0.60$ revealing the strong positive current advantage. The following values of other parameters were used to create the graphs: the length of the resource lifecycle, $T=10$; the coefficient of absolute risk aversion, $\gamma=0.5$; the discreteness with which resource capacity may be redeployed, $L=10$; the trends for returns, $\mu_{i i}=\mu_{j j}=0.1$; the variances of the innovation terms showing return volatilities, $\sigma_{i}^{2}=\sigma_{j}^{2}=0.45$; the correlation of the innovation terms capturing return correlation, $\rho=0$; the number of simulated paths for the returns, $n=10,000$; the risk-free interest rate, $r=0.1$; and the value of the invested resources, $V_{0}=1$. 


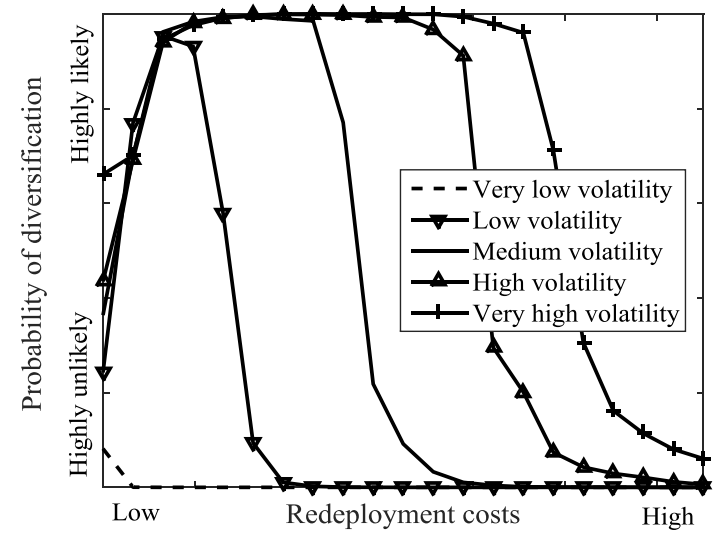

\section{A. Effects of redeployment costs and return volatility on the probability of corporate diversification}

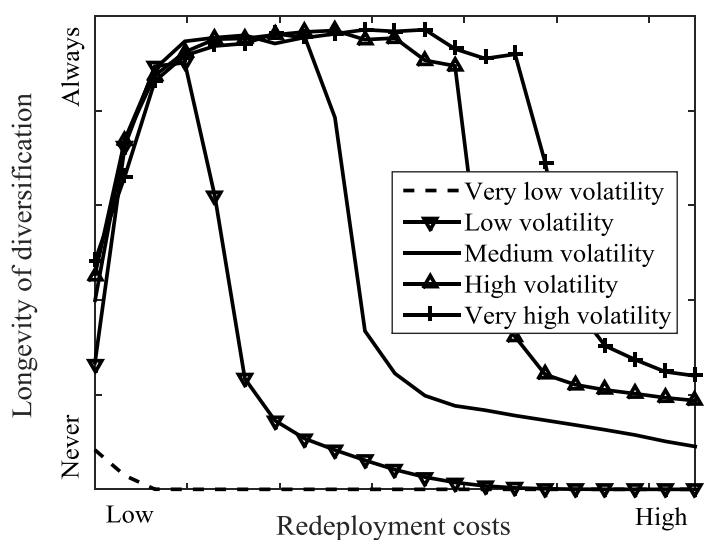

\section{B. Effects of redeployment costs and return volatility on the longevity of corporate diversification}

\section{Figure 3. Implications of redeployment costs and return volatility for the dynamics of corporate diversification}

Figure 3 shows the probability $p_{t}$ of the firm being diversified in markets $i$ and $j$ in the middle of the resources lifecycle (Panel A), and the average longevity

$\hat{l}$ of such diversification (Panel B). In both panels, the first (inverse) proxy for relatedness, the marginal redeployment cost $S$, represents inter-temporal economies of scope and varies within the interval $S \in[0.0,1.3]$. In particular, $S=0.0$ corresponds to the strongest possible relatedness between $i$ and $j$ in non-scale free resources, whereas $S=1.3$ corresponds to very weak relatedness. In both panels, the second proxy for relatedness, the sharing factor $\beta$, is set to the medium value $\beta=1.00$ with which knowledge relatedness is mediocre and intra-temporal diseconomies or economies are absent. In both panels, the variances $\sigma_{i}^{2}$ and $\sigma_{j}^{2}$ of the innovation terms capturing the volatilities of returns take five values. In particular, in the broken lines, $\sigma_{i}^{2}=\sigma_{j}^{2}=0.05$ capturing very low volatility. In the lines with downward-pointing triangles, $\sigma_{i}^{2}=\sigma_{j}^{2}=0.30$ revealing low volatility. In the solid lines, $\sigma_{i}^{2}=\sigma_{j}^{2}=0.45$ corresponding to moderate volatility. In the lines with upward-pointing triangles, $\sigma_{i}^{2}=\sigma_{j}^{2}=0.80$ corresponding to high volatility. In the lines marked with plus signs,

$\sigma_{i}^{2}=\sigma_{j}^{2}=1.05$ corresponding to very high volatility. The following values of other parameters were used to generate the graphs: the length of the resource lifecycle, $T=10$; the coefficient of absolute risk aversion, $\gamma=0.5$; the discreteness with which resource capacity may be redeployed, $L=10$; the offsets capturing the initial returns, $A_{i}=A_{j}=0.50$; the trends for returns, $\mu_{i i}=\mu_{j j}=0.1$; the correlation of the innovation terms capturing return correlation, $\rho=0$; the number of simulated paths for the returns, $n=10,000$; the risk-free interest rate, $r=0.1$; and the value of the invested resources, $V_{0}=1$. 


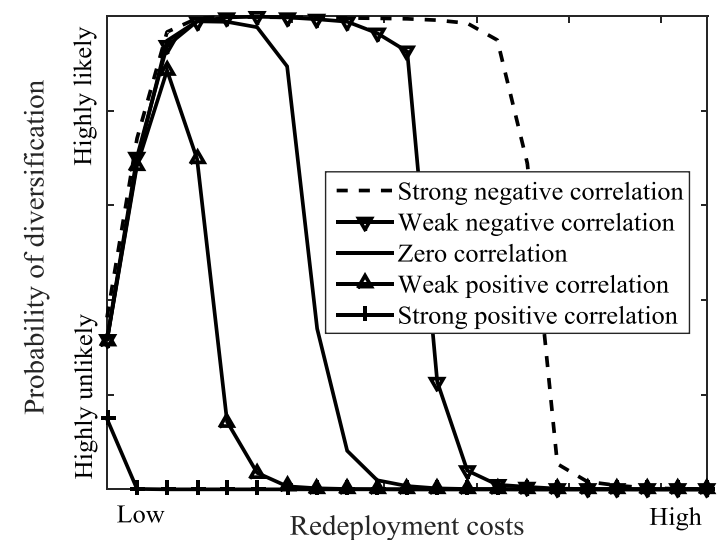

\section{A. Effects of redeployment costs and return correlation on the probability of corporate diversification}

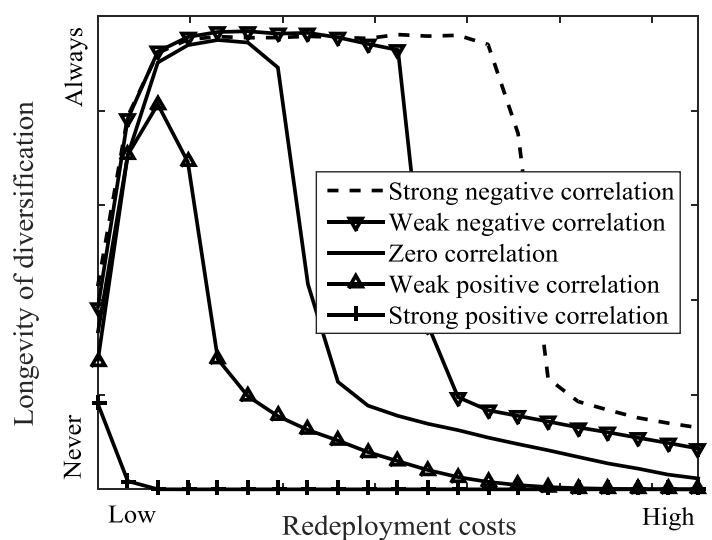

B. Effects of redeployment costs and return correlation on the longevity of corporate diversification

\section{Figure 4. Implications of redeployment costs and return correlation for the dynamics of corporate diversification}

Figure 4 shows the probability $p_{t}$ of the firm being diversified in markets $i$ and $j$ in the middle of the resources lifecycle (Panel A), and the average longevity

$\hat{l}$ of such diversification (Panel B). In both panels, the first (inverse) proxy for relatedness, the marginal redeployment cost $S$, represents inter-temporal economies of scope and varies within the interval $S \in[0.0,1.3]$. In particular, $S=0.0$ corresponds to the strongest possible relatedness between $i$ and $j$ in non-scale free resources, whereas $S=1.3$ corresponds to very weak relatedness. In both panels, the second proxy for relatedness, the sharing factor $\beta$, is set to the medium value $\beta=1.00$ with which knowledge relatedness is mediocre and intra-temporal diseconomies or economies are absent. In both panels, the correlation $\rho$ of the innovation terms capturing return correlation takes five values. In particular, in the broken lines, $\rho=-0.99$ representing strong negative correlation. In the lines with downward-pointing triangles, $\rho=-0.50$ revealing weak negative correlation. In the solid lines, $\rho=0.00$ representing zero correlation. In the lines with upward-pointing triangles, $\rho=0.50$ showing weak positive correlation. In the lines with plus signs, $\rho=0.99$ capturing strong positive correlation. The following values of other parameters were used to generate the graphs: the length of the resource lifecycle, $T=10$; the coefficient of absolute risk aversion, $\gamma=0.5$; the discreteness with which resource capacity may be redeployed, $L=10$; the offsets capturing the initial returns,

$A_{i}=A_{j}=0.50$; the trends for returns, $\mu_{i i}=\mu_{j j}=0.1$; the variances of the innovation terms capturing the volatilities of returns, $\sigma_{i}^{2}=\sigma_{j}^{2}=0.45 ;$ the number of simulated paths for the returns, $n=10,000$; the risk-free interest rate, $r=0.1$; and the value of the invested resources, $V_{0}=1$. 


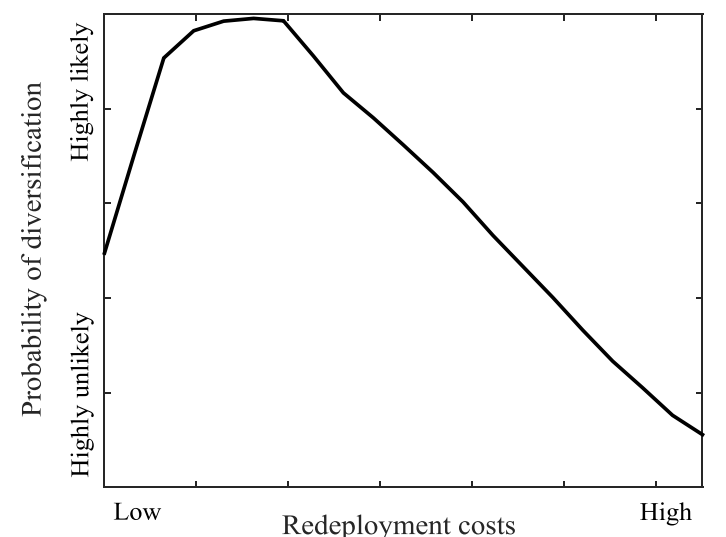

A. Long-run effect of redeployment costs on the
probability of corporate diversification

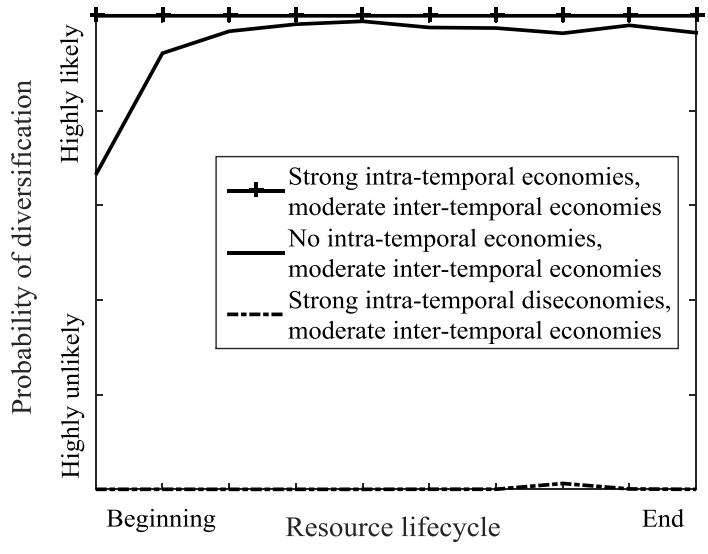

B. Evolution of the probability of corporate diversification over time

\section{Figure 5. Long-run implications of relatedness for the dynamics of corporate diversification}

Panel A of Figure 5 shows the probability $p_{T}$ of the firm being diversified in markets $i$ and $j$ in the end of the resources lifecycle. In Panel A, the first (inverse) proxy for relatedness, the marginal redeployment cost $S$, represents inter-temporal economies of scope and varies within the interval $S \in[0.0,1.3]$. In particular, $S=0.0$ corresponds to the strongest possible relatedness between $i$ and $j$ in non-scale free resources, whereas $S=1.3$ corresponds to very weak relatedness. In Panel $\mathrm{A}$, the second proxy for relatedness, the sharing factor $\beta$, is set to the medium value $\beta=1.00$ with which knowledge relatedness is mediocre and intra-temporal diseconomies or economies are absent. Panel B of Figure 5 shows the evolution of the probability $p_{t}$ of the firm being diversified in markets $i$ and $j$ over the resources lifecycle. In Panel B, the marginal redeployment cost takes an intermediate value $S=0.195$ representing moderate relatedness of non-scale free resources involved in inter-temporal economies. The sharing factor $\beta$ in Panel $\mathrm{B}$ takes three values. In particular, with $\beta=0.90$ (depicted with the broken line), $i$ and $j$ are very weakly related in knowledge, resulting in strong intra-temporal diseconomies of scope. With $\beta=1.00$ (depicted with the solid line), knowledge relatedness is average, generating neither diseconomies nor economies. With $\beta=1.10$ (depicted with the line with plus signs), $i$ and $j$ are very strongly related in knowledge, resulting in strong economies. In both panels, the following values of other parameters were used: the length of the resource lifecycle, $T=10$; the coefficient of absolute risk aversion, $\gamma=0.5$; the discreteness with which resource capacity may be redeployed, $L=10$; the offsets capturing the initial returns, $A_{i}=A_{j}=0.50$; the trends for returns, $\mu_{i i}=\mu_{j j}=0.1$; the variances of the innovation terms capturing the volatilities of returns, $\sigma_{i}^{2}=\sigma_{j}^{2}=0.45$; the correlation of the innovation terms capturing return correlation, $\rho=0$; the number of simulated paths for the returns, $n=10,000$; the risk-free interest rate, $r=0.1$; and the value of invested resources, $V_{0}=1$. 


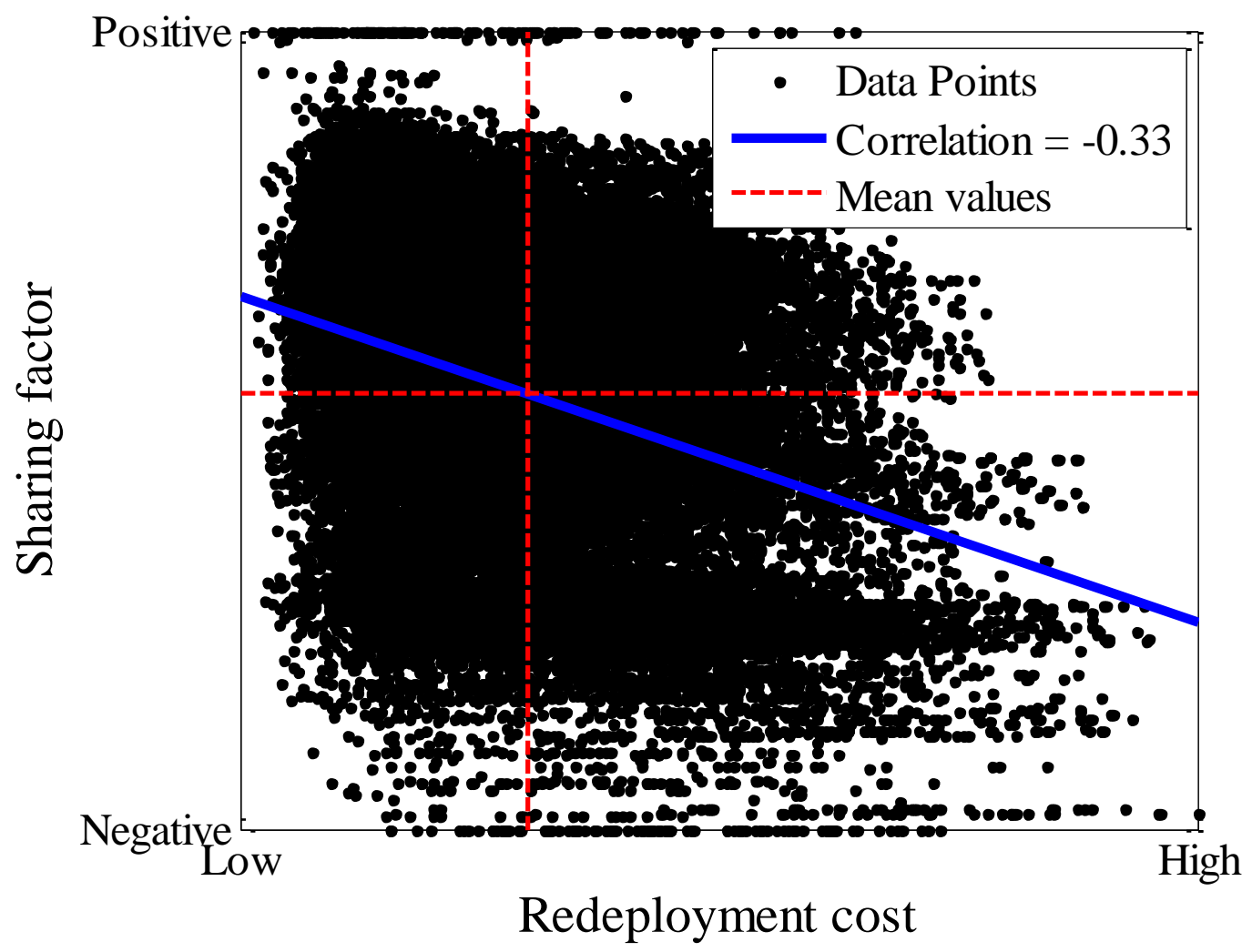

Figure 6. Relationship between two manifestations of relatedness in U.S. industries

Figure 6 presents the scatterplot for the joint distribution of the two ramifications of relatedness, the sharing factor and redeployment costs, across the U.S. industries. The sharing factor, representing relatedness in intra-temporal economies, is estimated using patent profiles of 3-digit U.S. SIC industries. That operationalization captures the similarity, between any two industries, in scale free technological knowledge classified into patent categories. Redeployment costs, capturing un-relatedness in inter-temporal economies, are represented using profiles of 3-digit U.S. SIC industries in terms of tangible resources. That operationalization measures the dissimilarity, between any two industries, in non-scale free resources classified into categories of tangible resources in Compustat balance sheet statements. 


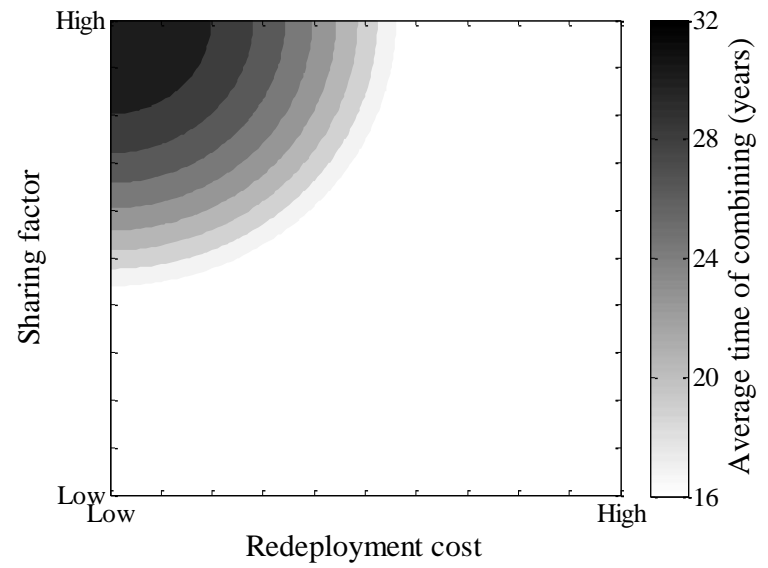

\section{A. Assumed diversification propensity versus sharing factor and redeployment cost}

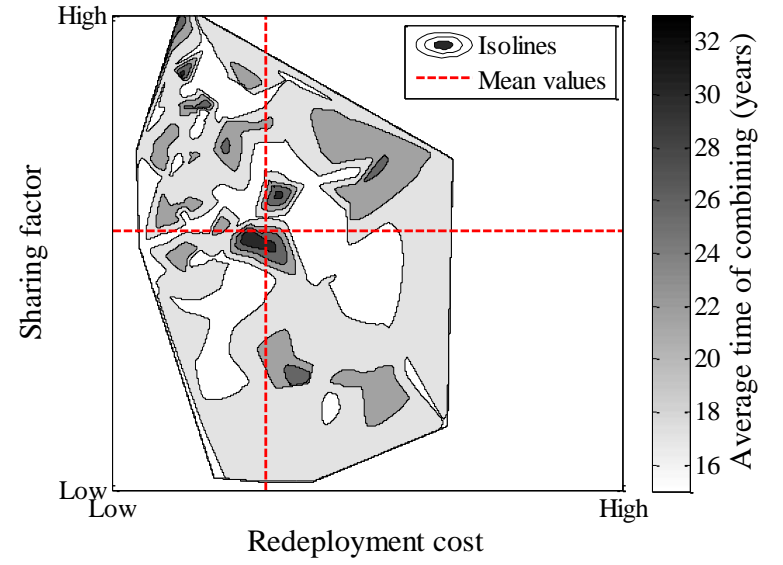

B. Actual diversification propensity versus sharing factor and redeployment cost

Figure 7. Diversification propensity in U.S. industries

Figure 7 presents filled contour maps showing the average time of combining different pairs of U.S. SIC industries against the two ramifications of relatedness. Panel A arbitrarily illustrates the previously assumed simple relationship, with which relatedness unambiguously enhances the diversification propensity. Panel B demonstrates the actual relationship occurring in the real U.S. industry data. The diversification propensity is computed as the average time of combining a pair of 3-digit U.S. SIC industries within a firm's scope based on the Compustat Segments data in years from 1976 to 2013 . The sharing factor, representing relatedness in intra-temporal economies, is estimated using patent profiles of 3-digit U.S. SIC industries. That operationalization captures the similarity, between any two industries, in scale free technological knowledge classified into patent categories. Redeployment costs, capturing un-relatedness in inter-temporal economies, are represented using profiles of 3-digit U.S. SIC industries in terms of tangible resources. That operationalization measures the dissimilarity, between any two industries, in non-scale free resources classified into categories of tangible resources in Compustat balance sheet statements. 
Table 1. Previous and novel insights into the implications of relatedness for the dynamics of corporate diversification

\begin{tabular}{|c|c|c|c|}
\hline $\begin{array}{l}\text { Questions on dynamics of } \\
\text { corporate diversification }\end{array}$ & $\begin{array}{l}\text { Limiting approaches } \\
\text { in extant research }\end{array}$ & $\begin{array}{l}\text { Specific implication in previous } \\
\text { research }\end{array}$ & Novel results \\
\hline $\begin{array}{l}\text { How does relatedness } \\
\text { affect the propensity of a } \\
\text { firm to diversify? }\end{array}$ & $\begin{array}{l}\text { Limited recognition of } \\
\text { different types of } \\
\text { economies of scope }\end{array}$ & $\begin{array}{l}\text { Relatedness monotonously } \\
\text { enhances the probability of } \\
\text { corporate diversification. }\end{array}$ & $\begin{array}{l}\text { The monotonous positive effect of } \\
\text { relatedness on the probability of } \\
\text { corporate diversification does not } \\
\text { hold with inter-temporal economies } \\
\text { of scope, wherein the probability of } \\
\text { diversification has an inverted U- } \\
\text { shape relationship with relatedness. }\end{array}$ \\
\hline $\begin{array}{l}\text { Does the restrictive focus } \\
\text { on relatedness suffice to } \\
\text { predict the proclivity of a } \\
\text { firm to diversify? }\end{array}$ & $\begin{array}{l}\text { Limited attention to } \\
\text { determinants of } \\
\text { economies of scope } \\
\text { other than relatedness }\end{array}$ & $\begin{array}{l}\text { The effect of relatedness on the } \\
\text { propensity of a firm to diversify is } \\
\text { unconditional (i.e., that effect does } \\
\text { not depend on other determinants of } \\
\text { economies of scope). }\end{array}$ & $\begin{array}{l}\text { The effect of relatedness on the } \\
\text { propensity of a firm to diversify } \\
\text { strongly interacts with inducements. }\end{array}$ \\
\hline $\begin{array}{l}\text { How does the propensity of } \\
\text { a firm to diversify evolve } \\
\text { over time? }\end{array}$ & $\begin{array}{l}\text { Verbal theorizing in the } \\
\text { complex context with } \\
\text { inter-temporal linkages } \\
\text { between corporate } \\
\text { diversification } \\
\text { decisions }\end{array}$ & $\begin{array}{l}\text { In the long run, the probability of } \\
\text { diversification is affected by } \\
\text { relatedness linked to intra-temporal } \\
\text { economies of scope but unaffected } \\
\text { by relatedness linked to inter- } \\
\text { temporal economies of scope. }\end{array}$ & $\begin{array}{l}\text { In the long run, the probability of } \\
\text { diversification is very sensitive to } \\
\text { relatedness present in inter-temporal } \\
\text { economies. Moreover, with } \\
\text { moderate levels of relatedness } \\
\text { involved in inter-temporal } \\
\text { economies of scope, the probability } \\
\text { of diversification due to such } \\
\text { economies remains very high by the } \\
\text { end of the resource lifecycle. }\end{array}$ \\
\hline
\end{tabular}


Table 2. Value dynamics over resources lifecycle

\begin{tabular}{|c|c|c|c|c|c|c|c|c|c|c|c|}
\hline Time $t$ & $t=0$ & $t=1$ & $t=2$ & $t=3$ & $t=4$ & $t=5$ & $t=6$ & $t=7$ & $t=8$ & $t=9$ & $t=T=10$ \\
\hline $\begin{array}{l}\text { Value } V_{k t} \\
\text { accumulated by } \\
\text { time } t\end{array}$ & $V_{k 0}$ & $V_{k 0}+V_{k 0} F_{k 1}$ & $\begin{array}{l}V_{k 0^{+}} \\
{\left[(1+r)^{1}-1\right] V_{k 0} F_{k 1}+} \\
V_{k 0} F_{k 2}\end{array}$ & $\begin{array}{l}V_{k 0^{+}} \\
{\left[(1+r)^{2}-1\right] V_{k 0} F_{k 1}+} \\
{\left[(1+r)^{1}-1\right] V_{k 0} F_{k 2}+} \\
V_{k 0} F_{3}\end{array}$ & $\begin{array}{l}V_{k 0^{+}} \\
{\left[(1+r)^{3}-1\right] V_{k 0} F_{k 1}+} \\
{\left[(1+r)^{2}-1\right] V_{k 0} F_{k 2^{+}}} \\
{\left[(1+r)^{1}-1\right] V_{k 0} F_{k 3}+} \\
V_{k 0} F_{k 4}\end{array}$ & $\begin{array}{l}V_{k 0^{+}} \\
{\left[(1+r)^{4}-1\right] V_{k 0} F_{k 1^{+}}} \\
{\left[(1+r)^{3}-1\right] V_{k 0} F_{k 2^{+}}} \\
{\left[(1+r)^{2}-1\right] V_{k 0} F_{k 3^{+}}} \\
{\left[(1+r)^{1}-1\right] V_{k 0} F_{k 4^{+}}} \\
V_{k 0} F_{k 5}\end{array}$ & $\begin{array}{l}V_{k 0^{+}} \\
{\left[(1+r)^{5}-1\right] V_{k 0} F_{k 1}+} \\
{\left[(1+r)^{4}-1\right] V_{k 0} F_{k 2}+} \\
{\left[(1+r)^{3}-1\right] V_{k 0} F_{k 3^{+}}} \\
{\left[(1+r)^{2}-1\right] V_{k 0} F_{k 4^{+}}} \\
{\left[(1+r)^{1}-1\right] V_{k 0} F_{k 5^{+}}} \\
V_{k 0} F_{k 6}\end{array}$ & $\mid \begin{array}{l}V_{k 0^{+}} \\
{\left[(1+r)^{6}-1\right] V_{k 0} F_{k 1^{+}}} \\
{\left[(1+r)^{5}-1\right] V_{k 0} F_{k 2^{+}}} \\
{\left[(1+r)^{-}-1\right] V_{k 0} F_{k 3^{+}}} \\
{\left[(1+r)^{3}-1\right] V_{k 0} F_{k 4^{+}}} \\
{\left[(1+r)^{2}-1\right] V_{k 0} F_{k 5^{+}}} \\
{\left[(1+r)^{-1}-1\right] V_{k 0} F_{k 0^{+}}} \\
V_{k 0} F_{k 7}\end{array}$ & $\begin{array}{l}V_{k 0^{+}} \\
{\left[(1+r)^{7}-1\right] V_{k 0} F_{k 1^{+}}} \\
{\left[(1+r)^{6}-1\right] V_{k 0} F_{k 2^{+}}} \\
{\left[(1+r)^{5}-1\right] V_{k 0} F_{k 3^{+}}} \\
{\left[(1+r)^{4}-1\right] V_{k 0} F_{k 4^{+}}} \\
{\left[(1+r)^{3}-1\right] V_{k 0} F_{k 5^{+}}} \\
{\left[(1+r)^{2}-1\right] V_{k 0} F_{k 6^{+}}} \\
{\left[(1+r)^{1}-1\right] V_{k 0} F_{k 7^{+}}} \\
V_{k 0} F_{k 8}\end{array}$ & $\begin{array}{l}V_{k 0^{+}} \\
{\left[(1+r)^{8}-1\right] V_{k 0} F_{k 1}+} \\
{\left[(1+r)^{7}-1\right] V_{k 0} F_{k 2^{+}}} \\
{\left[(1+r)^{6}-1\right] V_{k 0} F_{k 3^{+}}} \\
{\left[(1+r)^{5}-1\right] V_{k 0} F_{k 4^{+}}} \\
{\left[(1+r)^{-}-1\right] V_{k 0} F_{k 5^{+}}} \\
{\left[(1+r)^{3}-1\right] V_{k 0} F_{k 6^{+}}} \\
{\left[(1+r)^{2}-1\right] V_{k 0} F_{k 7^{+}}} \\
{\left[(1+r)^{1}-1\right] V_{k 0} F_{k 8^{+}}} \\
V_{k 0} F_{k 9}\end{array}$ & $\begin{array}{l}V_{k 0^{+}} \\
{\left[(1+r)^{9}-1\right] V_{k 0} F_{k 1^{+}}} \\
{\left[(1+r)^{8}-1\right] V_{k 0} F_{k 2}+} \\
{\left[(1+r)^{7}-1\right] V_{k 0} F_{k 3}+} \\
{\left[(1+r)^{6}-1\right] V_{k 0} F_{k 4^{+}}} \\
{\left[(1+r)^{5}-1\right] V_{k 0} F_{k 5} s^{+}} \\
{\left[(1+r)^{4}-1\right] V_{k 0} F_{k 6^{+}}} \\
{\left[(1+r)^{3}-1\right] V_{k 0} F_{k 7}+} \\
{\left[(1+r)^{2}-1\right] V_{k 0} F_{k 8^{+}}} \\
{\left[(1+r)^{1}-1\right] V_{k 0} F_{k 9^{+}}} \\
V_{k 0} F_{k 10}\end{array}$ \\
\hline $\begin{array}{l}\text { Value } V_{k T} \text { as } \\
\text { seen from time } t\end{array}$ & $\begin{array}{l}V_{k 0^{+}} \\
{\left[(1+r)^{9}-1\right] V_{k 0} F_{k 1^{+}}} \\
{\left[(1+r)^{8}-1\right] V_{k 0} F_{k 2^{+}}} \\
{\left[(1+r)^{7}-1\right] V_{k 0} F_{k 3^{+}}} \\
{\left[(1+r)^{6}-1\right] V_{k 0} F_{k 4^{+}}} \\
{\left[(1+r)^{5}-1\right] V_{k 0} F_{k 5^{+}}} \\
{\left[(1+r)^{4}-1\right] V_{k 0} F_{k 6^{+}}} \\
{\left[(1+r)^{3}-1\right] V_{k 0} F_{k 7^{+}}} \\
{\left[(1+r)^{2}-1\right] V_{k 0} F_{k s^{+}}} \\
{\left[(1+r)^{1}-1\right] V_{k 0} F_{k 9^{+}}} \\
V_{k 0} F_{k 10}\end{array}$ & $\begin{array}{l}V_{k 0^{+}} \\
{\left[(1+r)^{9}-1\right] V_{k 0} F_{k 1^{+}}} \\
{\left[(1+r)^{8}-1\right] V_{k 0} F_{k 2^{+}}} \\
{\left[(1+r)^{7}-1\right] V_{k 0} F_{k 3^{+}}} \\
{\left[(1+r)^{6}-1\right] V_{k 0} F_{k 4^{+}}} \\
{\left[(1+r)^{5}-1\right] V_{k 0} F_{k 5^{+}}} \\
{\left[(1+r)^{4}-1\right] V_{k 0} F_{k 6^{+}}} \\
{\left[(1+r)^{3}-1\right] V_{k 0} F_{k 7^{+}}} \\
{\left[(1+r)^{2}-1\right] V_{k 0} F_{k 8^{+}}} \\
{\left[(1+r)^{1}-1\right] V_{k 0} F_{k 9^{+}}} \\
V_{k 0} F_{k 10}\end{array}$ & $\begin{array}{l}V_{k 0^{+}} \\
{\left[(1+r)^{9}-1\right] V_{k 0} F_{k 1^{+}}} \\
{\left[(1+r)^{8}-1\right] V_{k 0} F_{k 2^{+}}} \\
{\left[(1+r)^{7}-1\right] V_{k 0} F_{k 3^{+}}} \\
{\left[(1+r)^{6}-1\right] V_{k 0} F_{k 4^{+}}} \\
{\left[(1+r)^{5}-1\right] V_{k 0} F_{k 5^{+}}} \\
{\left[(1+r)^{4}-1\right] V_{k 0} F_{k 6^{+}}} \\
{\left[(1+r)^{3}-1\right] V_{k 0} F_{k 7^{+}}} \\
{\left[(1+r)^{2}-1\right] V_{k 0} F_{k s^{+}}} \\
{\left[(1+r)^{1}-1\right] V_{k 0} F_{k 9^{+}}} \\
\boldsymbol{V}_{k 0} \boldsymbol{F}_{k 10}\end{array}$ & $\begin{array}{l}V_{k 0^{+}} \\
{\left[(1+r)^{9}-1\right] V_{k 0} F_{k 1}+} \\
{\left[(1+r)^{8}-1\right] V_{k 0} F_{k 2}} \\
{\left[(1+r)^{7}-1\right] V_{k 0} F_{k 3^{+}}} \\
{\left[(1+r)^{6}-1\right] V_{k 0} \boldsymbol{F}_{k 4^{+}}} \\
{\left[(1+r)^{5}-1\right] V_{k 0} \boldsymbol{F}_{k 5^{+}}} \\
{\left[(1+r)^{4}-1\right] V_{k 0} \boldsymbol{F}_{k 6^{+}}} \\
{\left[(1+r)^{3}-1\right] V_{k 0} \boldsymbol{F}_{k 7^{+}}} \\
{\left[(1+r)^{2}-1\right] V_{k 0} \boldsymbol{F}_{k 8^{+}}} \\
{\left[(1+r)^{1}-1\right] V_{k 0} \boldsymbol{F}_{k 9^{+}}} \\
\boldsymbol{V}_{\boldsymbol{k} 0} \boldsymbol{F}_{k 10}\end{array}$ & $\begin{array}{l}V_{k 0^{+}} \\
{\left[(1+r)^{9}-1\right] V_{k 0} F_{k 1^{+}}} \\
{\left[(1+r)^{8}-1\right] V_{k 0} F_{k 2}+} \\
{\left[(1+r)^{7}-1\right] V_{k 0} F_{k 3^{+}}} \\
{\left[(1+r)^{6}-1\right] V_{k 0} F_{k 4^{+}}} \\
{\left[(1+r)^{5}-1\right] V_{k 0} F_{k 5^{+}}} \\
{\left[(1+r)^{4}-1\right] V_{k 0} F_{k 6^{+}}} \\
{\left[(1+r)^{3}-1\right] V_{k 0} F_{k 7^{+}}} \\
{\left[(1+r)^{2}-1\right] V_{k 0} F_{k s^{+}}} \\
{\left[(1+r)^{1}-1\right] V_{k 0} F_{k 9^{+}}} \\
\boldsymbol{V}_{k 0} \boldsymbol{F}_{k 10}\end{array}$ & $\begin{array}{l}V_{k 0^{+}} \\
{\left[(1+r)^{9}-1\right] V_{k 0} F_{k 1^{+}}} \\
{\left[(1+r)^{8}-1\right] V_{k 0} F_{k 2^{+}}} \\
{\left[(1+r)^{7}-1\right] V_{k 0} F_{k 3^{+}}} \\
{\left[(1+r)^{6}-1\right] V_{k 0} F_{k 4^{+}}} \\
{\left[(1+r)^{5}-1\right] V_{k 0} F_{k 5} s^{+}} \\
{\left[(1+r)^{4}-1\right] V_{k 0} F_{k 6^{+}}} \\
{\left[(1+r)^{3}-1\right] V_{k 0} F_{k 7^{+}}} \\
{\left[(1+r)^{2}-1\right] V_{k 0} F_{k 8^{+}}} \\
{\left[(1+r)^{1}-1\right] V_{k 0} F_{k 9^{+}}} \\
\boldsymbol{V}_{k 0} \boldsymbol{F}_{k 10}\end{array}$ & 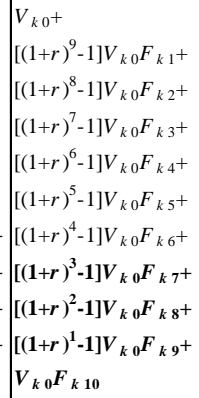 & 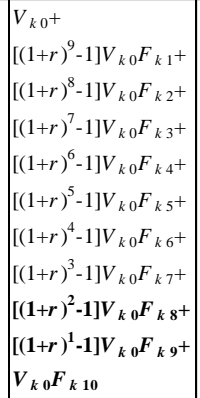 & \begin{tabular}{|l|}
$V_{k 0^{+}}$ \\
{$\left[(1+r)^{9}-1\right] V_{k 0} F_{k 1^{+}}$} \\
{$\left[(1+r)^{8}-1\right] V_{k 0} F_{k 2^{+}}$} \\
{$\left[(1+r)^{-}-1\right] V_{k 0} F_{k 3^{+}}$} \\
{$\left[(1+r)^{6}-1\right] V_{k 0} F_{k 4^{+}}$} \\
{$\left[(1+r)^{5}-1\right] V_{k 0} F_{k 5^{+}}$} \\
{$\left[(1+r)^{4}-1\right] V_{k 0} F_{k 6^{+}}$} \\
{$\left[(1+r)^{3}-1\right] V_{k 0} F_{k 7^{+}}$} \\
{$\left[(1+r)^{2}-1\right] V_{k 0} F_{k 8^{+}}$} \\
{$\left[(\mathbf{1}+\boldsymbol{r})^{1}-1\right] V_{k 0^{2}} \boldsymbol{F}_{k 9^{+}}$} \\
$\boldsymbol{V}_{\boldsymbol{k} \mathbf{0}} \boldsymbol{F}_{\boldsymbol{k}} \mathbf{1 0}$
\end{tabular} & $\begin{array}{l}V_{k 0^{+}} \\
{\left[(1+r)^{9}-1\right] V_{k 0} F_{k 1^{+}}} \\
{\left[(1+r)^{8}-1\right] V_{k 0} F_{k 2^{+}}} \\
{\left[(1+r)^{-}-1\right] V_{k 0} F_{k 3^{+}}} \\
{\left[(1+r)^{6}-1\right] V_{k 0} F_{k 4^{+}}} \\
{\left[(1+r)^{-5}-1\right] V_{k 0} F_{k 5^{+}}} \\
{\left[(1+r)^{4}-1\right] V_{k 0} F_{k 6^{+}}} \\
{\left[(1+r)^{3}-1\right] V_{k 0} F_{k 7^{+}}} \\
{\left[(1+r)^{2}-1\right] V_{k 0} F_{k 8^{+}}} \\
{\left[(1+r)^{1}-1\right] V_{k 0} F_{k 9^{+}}} \\
V_{k 0} F_{k 10}\end{array}$ & $\begin{array}{l}V_{k 0^{+}} \\
{\left[(1+r)^{9}-1\right] V_{k 0} F_{k 1}+} \\
{\left[(1+r)^{8}-1\right] V_{k 0} F_{k 2^{+}}} \\
{\left[(1+r)^{7}-1\right] V_{k 0} F_{k 3}+} \\
{\left[(1+r)^{6}-1\right] V_{k 0} F_{k 4^{+}}} \\
{\left[(1+r)^{5}-1\right] V_{k 0} F_{k 5} 5^{+}} \\
{\left[(1+r)^{4}-1\right] V_{k 0} F_{k 6^{+}}} \\
{\left[(1+r)^{3}-1\right] V_{k 0} F_{k 7^{+}}} \\
{\left[(1+r)^{2}-1\right] V_{k 0} F_{k 8^{+}}} \\
{\left[(1+r)^{1}-1\right] V_{k 0} F_{k 9^{+}}} \\
V_{k 0} F_{k 10}\end{array}$ \\
\hline $\begin{array}{l}\text { Value } \tilde{V}_{k T} \\
\text { relevant for } \\
\text { maximization of } \\
V_{k T} \text { at time } t\end{array}$ & $\begin{array}{l}{\left[(1+r)^{9}-1\right] V_{k 0} F_{k 1}+} \\
{\left[(1+r)^{8}-1\right] V_{k 0} F_{k 2}} \\
{\left[(1+r)^{7}-1\right] V_{k 0} F_{k 3^{+}}} \\
{\left[(1+r)^{6}-1\right] V_{k 0} F_{k 4^{+}}} \\
{\left[(1+r)^{5}-1\right] V_{k 0} F_{k 5^{+}}} \\
{\left[(1+r)^{4}-1\right] V_{k 0} F_{k 6^{+}}} \\
{\left[(1+r)^{3}-1\right] V_{k 0} F_{k 7^{+}}} \\
{\left[(1+r)^{2}-1\right] V_{k 0} F_{k 8^{+}}} \\
{\left[(1+r)^{1}-1\right] V_{k 0} F_{k 9^{+}}} \\
V_{k 0} F_{k 10}\end{array}$ & $\begin{array}{l}{\left[(1+r)^{8}-1\right] V_{k 0} F_{k 2}+} \\
{\left[(1+r)^{7}-1\right] V_{k 0} F_{k 3}+} \\
{\left[(1+r)^{6}-1\right] V_{k 0} F_{k 4}+} \\
{\left[(1+r)^{5}-1\right] V_{k 0} F_{k 5^{+}}} \\
{\left[(1+r)^{4}-1\right] V_{k 0} F_{k 6}+} \\
{\left[(1+r)^{3}-1\right] V_{k 0} F_{k 7^{+}}} \\
{\left[(1+r)^{2}-1\right] V_{k 0} F_{k 8^{+}}} \\
{\left[(1+r)^{1}-1\right] V_{k 0} F_{k 9}+} \\
V_{k 0} F_{k 10}\end{array}$ & $\begin{array}{l}{\left[(1+r)^{7}-1\right] V_{k 0} F_{k 3^{+}}} \\
{\left[(1+r)^{6}-1\right] V_{k 0} F_{k 4^{+}}} \\
{\left[(1+r)^{5}-1\right] V_{k 0} F_{k 5^{+}}} \\
{\left[(1+r)^{4}-1\right] V_{k 0} F_{k 6^{+}}} \\
{\left[(1+r)^{3}-1\right] V_{k 0} F_{k 7^{+}}} \\
{\left[(1+r)^{2}-1\right] V_{k 0} F_{k 8^{+}}} \\
{\left[(1+r)^{1}-1\right] V_{k 0} F_{k 9^{+}}} \\
V_{k 0} F_{k 10}\end{array}$ & $\begin{array}{l}{\left[(1+r)^{6}-1\right] V_{k 0} F_{k 4}+} \\
{\left[(1+r)^{5}-1\right] V_{k 0} F_{k 5^{+}}} \\
{\left[(1+r)^{4}-1\right] V_{k 0} F_{k 6^{+}}} \\
{\left[(1+r)^{3}-1\right] V_{k 0} F_{k 7^{+}}} \\
{\left[(1+r)^{2}-1\right] V_{k 0} F_{k 8^{+}}} \\
{\left[(1+r)^{1}-1\right] V_{k 0} F_{k 9}+} \\
V_{k 0} F_{k 10}\end{array}$ & $\begin{array}{l}{\left[(1+r)^{5}-1\right] V_{k 0} F_{k 5^{+}}} \\
{\left[(1+r)^{4}-1\right] V_{k 0} F_{k 6^{+}}} \\
{\left[(1+r)^{3}-1\right] V_{k 0} F_{k 7^{+}}} \\
{\left[(1+r)^{2}-1\right] V_{k 0} F_{k 8^{+}}} \\
{\left[(1+r)^{1}-1\right] V_{k 0} F_{k 9^{+}}} \\
V_{k 0} F_{k 10}\end{array}$ & $\left\{\begin{array}{l}{\left[(1+r)^{4}-1\right] V_{k 0} F_{k 6^{+}}} \\
{\left[(1+r)^{3}-1\right] V_{k 0} F_{k 7^{+}}} \\
{\left[(1+r)^{2}-1\right] V_{k 0} F_{k 8^{+}}} \\
{\left[(1+r)^{1}-1\right] V_{k 0} F_{k 9^{+}}} \\
V_{k 0} F_{k 10}\end{array}\right.$ & $\begin{array}{l}{\left[(1+r)^{3}-1\right] V_{k 0} F_{k 7^{+}}} \\
{\left[(1+r)^{2}-1\right] V_{k 0} F_{k 8^{+}}} \\
{\left[(1+r)^{1}-1\right] V_{k 0} F_{k 9^{+}}} \\
V_{k 0} F_{k 10}\end{array}$ & $\begin{array}{l}{\left[(1+r)^{2}-1\right] V_{k 0} F_{k 8^{+}}} \\
{\left[(1+r)^{1}-1\right] V_{k 0} F_{k 9^{+}}} \\
V_{k 0} F_{k 10}\end{array}$ & $\mid \begin{array}{l}{\left[(1+r)^{1}-1\right] V_{k 0} F_{k 9^{+}}} \\
V_{k 0} F_{k 10}\end{array}$ & $V_{k 0} F_{k 10}$ & \\
\hline
\end{tabular}

